\title{
ASSESSING THE EFFICIENCY OF CFRP DISCRETE CONFINEMENT SYSTEMS FOR CONCRETE CYLINDERS
}

\author{
Joaquim A. O. Barros ${ }^{1}$ and Débora R. S. M. Ferreira ${ }^{2}$
}

\begin{abstract}
Concrete columns requiring strengthening intervention always contain a certain percentage of steel hoops. Applying strips of wet lay-up carbon fiber reinforced polymer (CFRP) sheets in-between the existent steel hoops might, therefore, be an appropriate confinement technique with both technical and economic advantages, when full wrapping of a concrete column is taken as a basis of comparison. To assess the effectiveness of this discrete confinement strategy, circular cross section concrete elements confined by distinct arrangements of strips of CFRP sheet are submitted to a direct compression load up to the failure point. The influence of the width of the strip, distance between strips, number of CFRP layers per strip, CFRP stiffness and concrete strength class on the increase of the load carrying capacity and ductility of concrete columns, is evaluated.
\end{abstract}

An analytical model is developed to predict the compressive stress-strain relationship of concrete columns confined by discrete and continuous CFRP arrangements. The main results of the experimental program are presented and analyzed and used to assess the model performance.

CE Database subject headings: Carbon Fiber Reinforced Polymers, Confinement, Concrete, Columns, Confinement model.

\section{Introduction}

In recent years, fiber reinforced polymers (FRP) have been used to increase the load carrying and energy absorption capacities of reinforced concrete (RC) columns. The characteristics of FRP materials, including high specific strength and stiffness, low thickness and weight, and high resistance to corrosion are favorable properties justifying the increased use of these composites in structural rehabilitation and strengthening.

\footnotetext{
${ }^{1}$ Associate Professor, Dept. of Civil Engineering, Univ. of Minho, Campus de Azurém, 4810-058 Guimarães, Portugal. E-mail: barros@civil.uminho.pt

${ }^{2}$ PhD student, Dept. of Civil Engineering, Univ. of Minho, Campus de Azurém, 4810-058 Guimarães, Portugal.

E-mail: debora@ipb.pt
} 
The full FRP-wrapping technique is widely used to increase the load carrying capacity, the ductility and the shear strength of concrete columns (Mirmiran and Shahawy 1997, Toutanji 1999, Pessiki et al. 2001, Toutanji and Deng 2001, Berthet et al. 2005, Harajli et al. 2006). Since, in the majority of cases, concrete columns contain a certain percentage of steel hoops that may not necessarily comply with the actual code provisions, applying strips of FRP in-between the existent steel hoops appears to be an appropriate confinement technique with technical and economic advantages when full wrapping of the concrete column is taken as a basis of comparison. The present work is part of a research project aiming to establish design guidelines for the confinement of concrete columns with strips of wet lay-up carbon fiber reinforced polymer sheets (CFRP). Groups of series of direct compression tests on circular cross section concrete elements were carried out to assess the influence of CFRP strip width and spacing, layer numbers per strip, stiffness, and concrete strength class on the increment of the load carrying and energy absorption capacities of the column element.

Although several analytical confinement models have been proposed to simulate the stress-strain compression response of full FRP-wrapped concrete elements (Samaan et al. 1998, Spoelstra and Monti 1999, Toutanji and Deng 2001, Xiao and Wu 2000, Lam and Teng 2003, Li et al. 2003, Lin and Liao 2004, Harajli et al. 2006), there is a dearth of analytical models able to accurately predict the behavior of concrete columns confined by discrete CFRP arrangements. In the present work, the principles proposed by Harajli et al. (2006) were used to develop a confinement model to simulate not only full wrapped specimens, but also those with discrete arrangements. Performance of the model was appraised using results obtained in the experimental program.

\section{Confinement Systems and Test Groups}

The confinement systems are composed of epoxy resin bonded strips of wet lay-up CFRP sheets applied to concrete as well as to already existing CFRP sheet layers. Each specimen is designated as WiSjLk, where Wi represents the strip width, $\mathrm{S} j$ the number of strips along the specimen and $\mathrm{L} k$ the number of CFRP layers per strip. The confinement arrangements with one strip (S1) correspond to full wrapped specimens. Confinement procedures are described in detail elsewhere (Ferreira and Barros 2004). Tables 1 and 2 and Figs. 1 and 2 represent the experimental program, which is composed of three test group series. The first group is in Table 1 and Fig. 1 designated as G1_PC, and the second group is in Table 2 and Fig. 2 termed as G2_PC. Both groups involved direct compression tests with plain concrete (PC) cylinders of $300 \mathrm{~mm}$ height and $150 \mathrm{~mm}$ diameter. 
The G1_PC group aims to assess the effective CFRP volumetric ratio, $\rho_{f, e f}$, as well as the number of CFRP layers above which the increase of the cylinder load carrying capacity becomes marginal. The effective CFRP volumetric ratio is assumed as being the one that assures a constant post-peak compressive resistance (a perfect plastic behavior) for the confined specimen. Results from this group of tests were used to define the effective discrete confinement arrangements, taking into account the increase of the specimen load carrying capacity they can provide as well as cost and application time. These discrete confinement arrangements were used in the second and third (G3_RC) groups of tests where their performances were compared to the one provided by fully wrapping the concrete specimen.

In the G2_PC group of tests, the influence of the concrete compressive strength, stiffness of CFRP sheet and type of CFRP arrangement on the confinement provided by the selected effective confinement arrangements was evaluated for plain concrete specimens, while in the G3_RC group of tests the influence of these properties was assessed in RC cylinders of $600 \mathrm{~mm}$ height and $200 \mathrm{~mm}$ diameter.

The irregular top surface of the cylinder specimens of G1_PC and G2_PC test groups was ground to assure planarity between the specimen top and bottom surfaces and their orthogonal orientation with respect to the specimen axis. Likewise, a layer of epoxy resin-based bond product was applied to the G3_RC group of test specimens (Bonaldo et al. 2005) at the originally irregular specimen top surface since, due to their relatively large length, the available equipment could not grind the surface.

\section{Confinement Systems and Groups of Tests}

To evaluate the specimen axial compression strain, three displacement transducers (LVDTs) were positioned at 120 degrees around the specimen and registered the displacements between the loading steel plates of the equipment. This test setup avoids the addition of the testing equipment deformation to the values read by the LVDTs for the specimen deformation. Taking the values recorded by these transducers, the displacement of the specimen axis was determined for each scan reading and the corresponding strain was obtained through dividing this displacement by the measured specimen's initial height. To reduce the confinement effect on the specimen introduced by the machine load steel plates, a Teflon system was applied in-between the plates of the equipment and the specimen extremities. Strain gauges placed at half width of the strip were used to measure the strains in the CFRP sheet, which has fibers in orthogonal orientation to the specimen axis. The strip at specimen half height was monitored for the specimens confined with an odd number of strips, while the two strips nearest the specimen half height were monitored for those with an even number of strips (see Figs. 1 and 2). 


\section{Materials}

To evaluate the influence of the concrete strength class and the stiffness of the CFRP sheet on the confinement efficacy provided by the distinct CFRP arrangements, moderate and low strength concretes and two CFRP sheets of distinct fiber content were used in the experimental program. From uniaxial compression tests carried out at 28 days on concrete cylinders of $150 \mathrm{~mm}$ diameter and $300 \mathrm{~mm}$ height, average compressive strength of $23 \mathrm{MPa}$ and $16 \mathrm{MPa}$ was obtained for the moderate and low strength concretes of G2_PC group of tests, and $32 \mathrm{MPa}$ and $16 \mathrm{MPa}$ for the G3_RC group of tests. The specimens of G1_PC group of tests were made up of concrete with an average compressive strength of $23 \mathrm{MPa}$. In terms of concrete strength class, the experimental program, therefore, covers the range of concrete strength for the majority of concrete columns requiring on-site strengthening interventions.

CFRP sheets with the trade name of CF-130 (300 g/m $\mathrm{m}^{2}$ of fibers) and CF-120 (200 g/m $\mathrm{m}^{2}$ of fibers) were used in G2_PC and G3_RC groups of tests, while in G1_PC only CF-130 sheet was applied. According to the supplier, the CF130 and CF120 sheets have a thickness, $t_{f}$, of $0.176 \mathrm{~mm}$ and $0.117 \mathrm{~mm}$, respectively, an elasticity modulus and an ultimate strain in the fiber direction of about $240 \mathrm{GPa}$ and $1.5 \%$, respectively, and a tensile strength higher than $3800 \mathrm{MPa}$. To evaluate the properties of these CFRP sheets, samples of CFRP were tested according to ISO recommendations (2003). The obtained results are included in Table 3. The strain was measured from a clip gauge of $50 \mathrm{~mm}$ of measuring length and $0.5 \%$ accuracy. The tests were carried out under displacement control at a rate of $1 \mathrm{~mm} /$ minute. Thickness values of the sheets, included in Table 3, were used in the evaluation of both modulus of elasticity and tensile strength of the CFRP sheets.

To evaluate the tensile properties of the steel bars used in the G3_RC group of tests, five specimens for each bar diameter were tested according to the recommendations of EN 10002-1 (1996). The obtained results are included in Table 4.

\section{Selection of Effective Discrete Confinement Arrangements}

The G1_PC group of tests indicated in Table 1 was carried out to assess the CFRP volumetric ratio, $\rho_{f}$, of discrete arrangements that avoids the occurrence of a softening phase (i.e. for strain values larger than the strain at peak stress of the corresponding plain concrete elements, the load carrying capacity of the confined element increases up to the failure of the confinement system). Effective CFRP volumetric ratio, $\rho_{f, e}$, was the designation attributed to this value. The CFRP volumetric ratio is evaluated from: 


$$
\rho_{f}=4 \frac{W L S t_{f}}{D H}
$$

where $D$ represents the diameter of the cylinder cross section and $H$ is the height of the specimen. The tests of this group also seek to identify the number of layers above which the confinement effectiveness is marginal.

The relationship between concrete stress, $\sigma_{c}$, and concrete axial strain, $\varepsilon_{c}$, is shown in Fig. 3. For series W15S3 (three strips of $15 \mathrm{~mm}$ width), and for W30, W45 and W60 series (strips of 30, 45 and $60 \mathrm{~mm}$ width, respectively), the relationship between $\sigma_{c}$ and the CFRP strain in the fiber direction, $\varepsilon_{f}$, is also represented. Each curve of Fig. 3 represents the average response registered in the three specimens that comprise each series. The concrete stress is the ratio between the applied load and the specimen cross section.

From the analysis of Fig. 3 and the values of $\rho_{f}$ included in Table 1 it can be concluded that, to have an effective confinement, $\rho_{f}$ should be greater than $0.4 \%$. This percentage decreases if the concrete element to confine has some steel hoops. Comparing the responses of specimens of equal confinement ratio, such as W15S3L6 and W30S3L 3 of $\rho_{f}=0.42 \%$, W15S5L6 and W30S3L5 of $\rho_{f}=0.7 \%$, W45S4L3 and W60S3L 3 of $\rho_{f}=0.84 \%$, W45S4L5 and W60S3L5 of $\rho_{f}=1.4 \%$, and W45S4L7 and W60S3L7 of $\rho_{f}=1.98 \%$, it can be concluded that, the smaller the distance between strips, the larger the increase in terms of specimen load carrying and energy absorption capacities (herein designated by confinement effectiveness) provided by discrete confinement systems.

Figs. 3f and $3 \mathrm{~g}$ show that the application of a number of layers per strip higher than five is not effective. Therefore, in the G2_PC and G3_RC groups of tests (see Table 2 and Fig. 2) a number of five layers per strip was used (three and five layers were applied per strip), and the adopted discrete confinement arrangements were those in which the results from G1_PC group of tests showed as being the most promising to compete with fullwrapping in terms of specimen load carrying capacity and cost effectiveness.

\section{Test Group Series of Plain Concrete Specimens}

\section{Test series and confinement arrangements}

This group of test series (G2_PC of Table 2 and Fig. 2) is composed of concrete cylinders of two distinct concrete strength classes and two CFRP sheets of different stiffness, resulting in an experimental program consisting of C23S300, C23S200, C16S200 and C16S300 test series. In the designation attributed to a test group, C16 and C23 represent specimens of a concrete average compressive strength at 28 days, $f_{c o}$, of 16 and $23 \mathrm{MPa}$, respectively, while S200 and S300 indicate the type of CFRP sheet, $200 \mathrm{~g} / \mathrm{m}^{2}$ and $300 \mathrm{~g} / \mathrm{m}^{2}$, respectively. Each 
test series is composed of three distinct confinement arrangements represented in Fig. 2: W45S4 (four strips of $45 \mathrm{~mm}$ width), W60S3 (three strips of $60 \mathrm{~mm}$ width) and W300S1 (one strip of $300 \mathrm{~mm}$ width). Each one of these arrangements is constituted of two series, one of three layers per strip (L3) and the other of five layers (L5).

\section{Experimental results}

Fig. 4 shows the $\sigma_{c}-\varepsilon_{c}$ and $\sigma_{c}-\varepsilon_{f}$ curves for the C23S300, C23S200, C16S200 and C16S300 series of tests. The obtained curves and results in Table 5 show that the specimen load carrying capacity significantly increases when $\rho_{f}$ increases. The stress-strain relationship of a confined specimen, up to a stress level corresponding to the compressive strength of the corresponding unconfined specimen (UC), is practically unaffected by the presence of the CFRP. In general, the $\sigma_{c}-\varepsilon_{c}$ relationship of the confined specimens is composed of two quasi-linear branches, connected by a transition nonlinear branch, which is more pronounced in the C23 concrete group.

The values of $f_{c c} / f_{c o}, \varepsilon_{c d} / \varepsilon_{c o}, U_{c d} / U_{c o}$ and $\varepsilon_{f m a x} / \varepsilon_{f u}$ ratios of the G2_PC group of test series are indicated in Table 5. The concept of $f_{c c}, f_{c o}, \varepsilon_{c c}, \varepsilon_{c o}, U_{c c}$ and $U_{c o}$ is schematically represented in Fig. 5, $\varepsilon_{f m a x}$ is the maximum tensile strain in the CFRP fiber's direction and $\varepsilon_{f u}$ is the CFRP ultimate strain indicated in Table 3. Note that $U_{c c}$ and $U_{c o}$ is the energy dissipated in the softening phase of the confined and the corresponding unconfined specimen, respectively. The values of ratios included in Table 5 indicate that, as the concrete strength class decreases and the CFRP stiffness increases, the effectiveness of a confinement system increases in terms of the specimen load carrying capacity, deformability and energy absorption capacity. In the W45S4 and W60S3 series, of equal $\rho_{f}$, the confinement was more effective in the W45S4 series since the free space between the CFRP strips is smaller in this series, which means that more concrete volume was effectively confined. A high scatter was registered on the maximum strain values in the CFRP at failure of the specimens, since the recorded values only represent the areas where the strain gauges are placed and, consequently, they are too dependent on the specimen failure mode configuration. In the series W300S1L5 of the C23S300 test group, the maximum capacity of the machine was attained without rupture of the specimens of this series.

\section{Test Group Series of Reinforced Concrete Column Elements}

\section{Test series and confinement arrangements}

This group of tests, designated as G3_RC in Table 2 and Fig. 2, is composed of four test series for assessing the influence of concrete strength class and CFRP stiffness on confinement performance provided by the two 
discrete confinement and full-wrapping arrangements. The specimens of C16S200\$10 and C16S300 10 series were manufactured with concrete of an average compressive strength, $f_{c m}$, of $16 \mathrm{MPa}$ at 28 days (in cylinders of

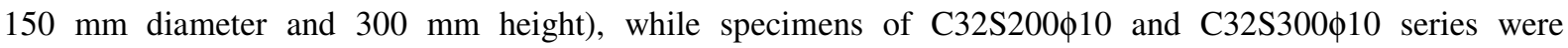
manufactured with concrete of $f_{c m}=32 \mathrm{MPa}$. All specimens were longitudinally reinforced with four steel bars of $10 \mathrm{~mm}$ diameter $\left(\rho_{s l}=A_{s l} / A_{g}=1.0 \%\right.$, where $A_{s l}$ and $A_{g}$ are the cross section area of the longitudinal bars and the specimen, respectively), and were transversally reinforced with steel hoops of $6 \mathrm{~mm}$ diameter, spaced at $120 \mathrm{~mm}$. The values of the evaluated tensile properties of these bars are included in Table 4 .

\section{Experimental Results}

Figs. 6 to 8 include the $\sigma_{c}-\varepsilon_{c}$ and $\sigma_{c}-\varepsilon_{f}$ curves for the tested specimens. Tables 6 and 7 include the main effectiveness indicators provided by the applied confinement systems. In the label used to designate the specimens, the characters indicating the number of CFRP strips (S4) were removed, since four strips were applied in every RC column element confined by discrete arrangements. In these tables, $f_{c o, U P C}$ is the compressive strength of unconfined plain concrete specimens (UPC), $f_{c o, U R C}$ is the compressive strength of unconfined reinforced concrete specimens, $\varepsilon_{c o, U P C}$ is the specimen axial strain corresponding to $f_{c o, U P C}$ and $\varepsilon_{c o, U P C}$ is the specimen axial strain corresponding to $f_{c o, U R C}$. Each value in Tables 6 and 7 is the average of results obtained on the two specimens of each series. In specimens W600L5 of C32S200\$10 and C32S300\$10 series and in specimens W600L3 of C32S300\$10 series (fully wrapped specimens) the maximum load carrying capacity of the equipment was attained without failure of these specimens. The values indicated in Table 7 correspond to the end of this test phase. Since the load carrying capacity of the equipment can be doubled if the tests are carried out in a non-closed loop control, the specimens of these series were again tested up to their failure, and the attained $f_{c c}$ values are indicated in Table 7 within square brackets. As it was impossible to record strains in the CFRP during this second loading phase of these tests, only the compressive strength was recorded. In specimens W600L3 of C32S200\$10 the equipment load carrying capacity was also attained but, since this load was maintained during a certain period of time during which the axial deformation of the specimens and the CFRP deformation increased, the specimens finally failed. The graphs of Fig. 6 primarily show the influence of the concrete compressive strength on the confinement effectiveness provided by the adopted arrangements. For the specimens of low strength concrete, a $\sigma_{c}-\varepsilon_{c}$ of pronounced nonlinear relationship occurred just after $\varepsilon_{c o, U R C}$. For the specimens of higher strength concrete, however, a significant branch with a stiffness similar to that of the corresponding URC specimen in its pre-peak phase developed before the transition phase governed by the 
stiffness of the CFRP confinement arrangement. The length of this branch increased with the rise of $\rho_{f}$ and the decrease of the volume of unconfined concrete, i.e. decrease of the distance between the CFRP strips.

However, the axial strain at specimen failure was lower in specimens of higher concrete compressive strength, since, due to the larger dilation of this concrete, the CFRP failure strain was attained for lower specimen axial strains. In Fig. 7 results highlight the influence of the CFRP stiffness. This latter figure shows that, for the C16 concrete specimens, in general, increasing the CFRP stiffness resulted in an increase of $f_{c c}$ and $\varepsilon_{c c}$, whereas the stiffness of the $\sigma_{c}-\varepsilon_{c}$ response was marginally increased after a strain value of about $\varepsilon_{c o, U R C}$. In terms of CFRP maximum strain, $\varepsilon_{f m a x}$ of S300 confined specimens was larger than $\varepsilon_{f m a x}$ of S200 specimens. Although the previous observations can be reproduced for C32 specimens, the influence of the CFRP stiffness in the $\sigma_{c}{ }^{-} \varepsilon_{c}$ response was larger for the $\mathrm{C} 32$ specimens. Since this concrete is more brittle than the C16 low strength concrete, the higher dilation of the $\mathrm{C} 32$ concrete more efficiently mobilized the potential confinement of the stiffer CFRP sheets at its softening phase.

In Fig. 8, the $\sigma_{c}-\varepsilon_{c}$ and $\sigma_{c}-\varepsilon_{f}$ curves are presented in order to show the influence of the type of confinement arrangement on compression behavior of the tested RC cylinders. This figure reveals that $f_{c c}$ augmented with the increase of $\rho_{f}$, and, in general, $\varepsilon_{c c}$ and $\varepsilon_{f m a x}$ also increased with $\rho_{f}$, especially in specimens of discrete confinements. Comparing W45L5 of C16S300ф10 with W600L3 of C16S200ф10, and W45L5 of C32S300ф10 with W600L3 of C32S200\$10, that have a similar $\rho_{f}$, it may be concluded that confinement efficiency was higher in the fully wrapped specimens.

Results of Table 6 indicate that, in C16S200\$10, $f_{c c} / f_{c o, U R C}$ varied from 1.7 in series confined with strips of $45 \mathrm{~mm}$ width and three layers per strip (W45S5L3), $\rho_{f}=0.25 \%$, up to 3.6 in the fully-wrapped series with five layers, $\rho_{f}=1.14 \%$. For $\mathrm{C} 16 \mathrm{~S} 300 \phi 10$ these limit values increased to 2.0 and 4.8 , respectively, since the CFRP confinement ratio increased due to the higher thickness of the CF130 sheet (from $\rho_{f}=0.40 \%$ up to $\rho_{f}=1.76 \%$ ). Table 7 shows that, in the case of $\mathrm{C} 32 \mathrm{~S} 200 \phi 10, f_{c c} / f_{c o, U R C}$ varied from 1.28 for $\rho_{f}=0.25 \%$ up to 2.95 for $\rho_{f}=1.14 \%$, while for $\mathrm{C} 32 \mathrm{~S} 300 \phi 10$ the values were in the range 1.38 to 3.27 for $\rho_{f}=0.4 \%$ and $\rho_{f}=1.76 \%$, respectively. In terms of $\varepsilon_{c c} / \varepsilon_{c o, U R C}$, the values ranged from 6.4 up to 12.1 for C16S200ф10 series, 8.5 up to 16.1 for $\mathrm{C} 16 \mathrm{~S} 300 \phi 10,2.3$ up to 4.2 for $\mathrm{C} 32 \mathrm{~S} 200 \phi 10$ and 3.2 up to 5.0 for $\mathrm{C} 16 \mathrm{~S} 300 \phi 10$. However, the upper bound values of the ranges of $\varepsilon_{c c} / \varepsilon_{c o, U R C}$ for these last two series of tests would have been greater if the strains in the CFRP of the specimens, that have not failed in the closed loop control test phase, had been recorded in the nonclosed loop control phase. In all series of tests, the increase of $\varepsilon_{c c} / \varepsilon_{c o, U R C}$ ratio with $\rho_{f}$ was more pronounced in 
specimens of discrete confinement arrangements than in fully-wrapped specimens. The plastic deformation of the concrete in-between the CFRP strips may justify this occurrence.

All specimens failed by CFRP tensile rupture and the last column of Tables 6 and 7 shows that the maximum tensile strain in the direction of the fibers, $\varepsilon_{f m a x}$, varied from $38 \%$ up to $85 \%$ of the CFRP ultimate tensile strain, $\varepsilon_{f u}$. These values are only for specimens that failed when the equipment was working in closed-loop control. As Lam and Teng (2003) have already reported, the variation of the strain field in the CFRP depends considerably on the distribution of the damage in the concrete specimen. Taking this into account and considering that only one or two strain gauges were applied per specimen for recording the CFRP strain variation, it is not surprising that a general tendency could not be determined for the $\varepsilon_{f m a x} / \varepsilon_{f u}$ ratio. A high scatter was registered on the maximum strain values in the CFRP, since the recorded values only represent the areas where the strain gauges were placed. Hence, these values are too dependent on the specimen failure mode configuration.

\section{Modeling}

The analytical model proposed in the present work is based on the two stress-strain branches schematically represented in Fig. 9. Point A, characterized by an $\varepsilon_{c A}$ strain and an $f_{c A}$ stress, separates the domain between a marginal and a significant influence of the effective lateral confining pressure provided by the CFRP confinement arrangements, $f_{f l}$. Since concrete volumetric expansion starts to occur before the compressive strength of unconfined concrete specimens, point A is evaluated for a certain minimum value of the CFRP strain, $\varepsilon_{f}$. The $\sigma_{c}-\varepsilon_{c}$ curves of Figs. 6 to 8 show that in specimens of low concrete compressive strength $\varepsilon_{c A}$ and $f_{c A}$ can be assumed to be equal to $\varepsilon_{c o, U R C}$ and $f_{c o, U R C}$, respectively, since the concrete dilation before peak compressive strength is marginal, thereby not activating significant lateral confinement in the CFRP systems. However, for the maximum concrete compressive strength used in the present work, a better simulation of the experimental results is obtainable if a certain minimum lateral confinement is used to define $\varepsilon_{c A}$ and $f_{c A}$. Based on the strains measured in the CFRP at the specimen axial level corresponding to $\varepsilon_{c o, U R C}$, a value of about $3.0 \times 10^{-5}$ was assumed for $\varepsilon_{f}$ to define $\varepsilon_{c A}$ and $f_{c A}$. To obtain $\varepsilon_{c A}$ and $f_{c A}$, as well as the $\sigma_{c}{ }^{-} \varepsilon_{c}$ points that define the second branch, the following equations are used (Harajli et al. 2006):

$$
\begin{gathered}
\sigma_{c}=f_{c o, U R C}+k_{1} f_{l} \text { for } \varepsilon_{c} \geq \varepsilon_{c A} \\
\varepsilon_{c}=\varepsilon_{c o, U R C}\left[1+k_{2}\left(\frac{\sigma_{c}}{f_{c o, U R C}}-1\right)\right] \text { for } \varepsilon_{c} \geq \varepsilon_{c A}
\end{gathered}
$$


where

$$
f_{l}=f_{f l}+f_{s l} \frac{A_{c c}}{A_{g}}
$$

is the effective lateral confinement pressure, and $k_{1}$ and $k_{2}$ and two parameters that are obtained from the experimental results recorded in the G3_RC group of tests. In Eq. (4) $f_{f l}$ and $f_{s l}$ represent the effective lateral confining pressure exerted by CFRP and ordinary steel hoops, respectively, and can be determined from the following equations:

$$
\begin{gathered}
f_{f l}=\frac{\alpha_{f e} \alpha_{f v} \rho_{f} E_{f}}{2} \varepsilon_{f} \\
f_{s l}=\frac{\alpha_{s e} \alpha_{s v} \rho_{s t}}{2} f_{s y t}
\end{gathered}
$$

where $\rho_{f}$ is the CFRP volumetric ratio, $E_{f}$ is the CFRP elasticity modulus, $\rho_{s t}$ is the volumetric ratio of steel hoops (Mander et al. 1988), $\alpha_{f e}$ and $\alpha_{f v}$ are the coefficients that account for the effectiveness of the FRP systems in confining the concrete along the plane of the specimen cross section, and the concrete between FRP strips, respectively (Mander et al. 1988):

$$
\alpha_{f v}=\frac{\left(1-\frac{s_{f}}{2 D}\right)^{2}}{1-\frac{A_{s l}}{A_{g}}}
$$

and $\alpha_{s e}$ and $\alpha_{s v}$ are the coefficients that account for the effectiveness of the steel hoops in confining the concrete along the plane of the specimen cross section, and the concrete between steel hoops, respectively (Mander et al. 1988):

$$
\alpha_{s v}=\frac{\left(1-\frac{s_{s}}{2 d_{s t}}\right)^{2}}{1-\frac{A_{s l}}{A_{g}}}
$$

For circular columns $\alpha_{f e}=\alpha_{v e}=1.0$, and for full wrapping configuration $\alpha_{f i}=1.0$. In Eqs. (7) $s_{f}$ and $D$ are, respectively, the clear spacing between consecutive FRP strips (for full wrapping $s_{f}=0$ ) and the diameter of the specimen cross section, while $s_{s}$ and $d_{s t}$ of Eq. (8) are, respectively, the steel hoop spacing and the diameter of the steel hoop (120 mm and $160 \mathrm{~mm}$, respectively, for the specimens of G3_RC group of tests). In these two 
equations, $A_{s l}$ is the cross section area of the longitudinal reinforcement and $A_{g}$ is the area of the specimen cross section.

To obtain values for $k_{l}$ of Eq. (2), the results obtained experimentally between $k_{l}=\left(\sigma_{c}-f_{c o, U R C}\right) / f_{l}$ and $f_{l} l f_{c o, U R C}$ are plotted in Fig. 10. The size of the markers, which was used to distinguish values between the four series of G3_RC group of tests, is proportional to $\rho_{f}$. The results of this figure show that, for $f_{l} / f_{c o, U R C}$ up to of about 0.15 , $k_{l}$ has a tendency to increase with the increase of the concrete compressive strength, and, in general, for each concrete strength class, the higher $k_{l}$ was, the larger $\rho_{f}$ tended to be, which can be justified by the tendency that concrete has for having higher dilation along with larger compressive strength. For the C16 and C32 concrete strength levels adopted in the present work (this range is representative of the concrete of structures requiring strengthening intervention) the following equations for $k_{l}$ were obtained:

$$
\begin{gathered}
k_{1}=a\left(\frac{f_{l}}{f_{c o, U R C}}\right)^{-b} \\
a=2.9+72.848\left(\rho_{f}-0.0025\right) ; b=0.2177 \text { for C16 and } \rho_{f} \in[0.0025 ; 0.0176] \\
a=2.0+125.828\left(\rho_{f}-0.0025\right) ; b=0.42-7.947\left(\rho_{f}-0.0025\right) \text { for } \mathrm{C} 32 \text { and } \\
\rho_{f} \in[0.0025 ; 0.0176]
\end{gathered}
$$

For concrete specimens of $f_{c o, U R C}$ inside of the strength range of $\mathrm{C} 16$ and $\mathrm{C} 32$ the $k_{l}$ value can be obtained from linear interpolation using the $k_{l}$ values determined from (9).

To obtain values for $k_{2}$ of Eq. (3), the results obtained experimentally between $k_{2}=\left(\varepsilon_{c} / \varepsilon_{c o, U R C}-1\right) /\left(\sigma_{c} / f_{c o, U R C}-1\right)$ and $\varepsilon_{f}$ are plotted in Fig. 11. Results of this figure demonstrate that $k_{2}$ has a tendency to increase with decreasing concrete compressive strength, and, that for each concrete strength class the variation of $k_{2}$ with $\varepsilon_{f}$ tends to become larger with decreasing $\rho_{f}$. In fact, the maximum concrete axial deformability increases with the decrease of the concrete strength class since the concrete post-peak brittleness decreases with the decrease of the concrete compressive strength, which justifies the reported tendency between $k_{2}$ and $\varepsilon_{f}$. Furthermore, the concrete transversal deformation tends to increase with the decrease of $\rho_{f}$, resulting in a larger axial concrete deformation. Based on the obtained results, the following equations were obtained for $\mathrm{C} 16$ and $\mathrm{C} 32$ concrete strength classes, respectively: 


$$
\begin{aligned}
& k_{2}=\left[555-29006\left(\rho_{f}-0.0025\right)\right] \varepsilon_{f}+2.0 \text { for } \mathrm{C} 16 \text { and } \rho_{f} \in[0.0025 ; 0.0176] \\
& k_{2}=\left[600-28695\left(\rho_{f}-0.0025\right)\right] \varepsilon_{f}+1.0 \text { for } \mathrm{C} 32 \text { and } \rho_{f} \in[0.0025 ; 0.0176]
\end{aligned}
$$

For concrete specimens of $f_{c o, U R C}$ inside of the strength range of C16 and C32 the value of $k_{2}$ can be obtained from linear interpolation using the $k_{2}$ values determined from (10) and (11).

For the first branch, either the second-degree parabola proposed by Mander et al. (1998) or the $\sigma_{c}-\varepsilon_{c}$ equation recommended by CEB-FIP Model Code (1990) can be used. In the present work, however, a third-degree equation was used in order to fit the first branch with higher accuracy:

$$
\begin{gathered}
\sigma_{c}=B \varepsilon_{c}^{3}+C \varepsilon_{c}^{2}+E_{c i} \varepsilon_{c} \text { for } \varepsilon_{c}<\varepsilon_{c A} \\
B=-\frac{2}{\varepsilon_{c A}^{3}} D \\
C=\frac{E_{c A}}{2 \varepsilon_{c A}}-\frac{E_{c i}}{2 \varepsilon_{c A}}+\frac{3}{\varepsilon_{c A}^{2}} D \\
D=f_{c A}-0.5 \varepsilon_{c A}\left(E_{c i}+E_{c A}\right)
\end{gathered}
$$

where $E_{c A}$ is the tangent of the second branch at point A (see Fig. 9):

$$
E_{c A}=\left.\frac{d \sigma_{c}}{d \varepsilon_{c}}\right|_{\varepsilon_{c}=\varepsilon_{c A}}=\frac{f_{c A}}{k_{2 R} \varepsilon_{c A}}
$$

and $k_{2 R}$ is the value of $k_{2}$ obtained for $\varepsilon_{f}=0.3 \%$ in order to assure continuity, as much as possible, between tangents to the two $\sigma_{c}-\varepsilon_{c}$ branches, at point $\mathrm{A}$.

Adopting for $\varepsilon_{c o, U R C}, f_{c o, U R C}$ and $E_{c i}$ the values obtained from the stress-strain curves of the URC specimens, the analytical and experimental stress-strain axial relationships $\left(\sigma_{c}-\varepsilon_{c}\right)$ are compared in Fig.12, from which it can be concluded that the developed model simulates the experimentally obtained $\sigma_{c}-\varepsilon_{c}$ curves with good accuracy. In this figure, compressive strains and stresses are considered as positive values.

\section{Summary and Conclusions}

To compare the efficiency of discrete and continuous confinement CFRP systems for concrete column elements, three groups of series of direct compression tests were carried out. The first group was composed of concrete 
cylinders of $150 \mathrm{~mm}$ diameter and $300 \mathrm{~mm}$ height, tested to obtain the effective CFRP volumetric confinement ratio, $\rho_{f, e f}$, which is the one that provides an increase in specimen load carrying capacity when the compressive strength of its corresponding unconfined specimens is taken as a basis of comparison. Results showed that the specimen load carrying capacity increased with the CFRP confinement ratio, and that $\rho_{f, e f}$ should be greater than $0.4 \%$. This group of tests also aimed at obtaining the number of CFRP layers above which the confinement effectiveness is questionable from a mechanical and an economic point-of-view. The results revealed that above five layers, the increment in terms of load carrying capacity, deformability and energy absorption capacity were all marginal.

A second group of test series with plain concrete cylinders of $150 \mathrm{~mm}$ diameter and $300 \mathrm{~mm}$ height was carried out to assess the influence of the concrete strength class and the stiffness of the CFRP sheet on the confinement performance provided by two effective discrete confinement arrangements and a full-wrapping arrangement. Results showed that the specimen load carrying capacity, its deformability and its energy absorption capacity tended to be higher as the concrete strength was lower and the stiffness of the CFRP sheet was larger. In series of equal $\rho_{f}$ the confinement was more effective in series of smaller free space between the CFRP strips.

A third group of test series was executed with reinforced concrete cylinders of $200 \mathrm{~mm}$ diameter and $600 \mathrm{~mm}$ height, that had a current percentage of steel hoops, to assess the influence of the concrete strength class and the stiffness of the CFRP sheet in the confinement performance provided by two effective discrete confinement arrangements and a full-wrapping arrangement. The concrete compressive strength, the CFRP stiffness and the volume of unconfined concrete had a significant influence on the shape of the specimen stress-axial strain response.

High values of maximum strain at the CFRP fiber direction were recorded in specimens of concrete of higher compressive strength since concrete dilation, after concrete crack initiation, increases with its compressive strength thereby more efficiently activating the potential confinement of the stiffer CFRP sheets.

As compared to the full-wrapping confinement arrangement, partial confinement arrangements were not as effective in terms of load carrying capacity, but provided a significant increase of the load carrying capacity (up to three times the compressive strength of its corresponding unconfined specimen, for $\rho_{f}=0.88 \%$ ), assured a high level of deformability at the specimen failure (up to sixteen times the strain at the compressive strength of its corresponding unconfined specimen, for $\rho_{f}=0.88 \%$ ), were easier and faster to apply and consumed less CFRP and epoxy adhesive materials. 
A stress-strain analytical model was developed using results of the third group of tests to calibrate two parameters defining the FRP contribution for the increase of both the load carrying capacity and deformability of reinforced concrete columns. This model accurately predicted the stress-strain relationships recorded in the series of the third group of tests.

\section{Acknowledgements}

The authors of the present work wish to acknowledge the generous support provided by S\&P Clever Reinforcement and MBT Bettor Portugal. The second author would like to thank the financial support by PRODEP action 5.3/N/199.014/01. 


\section{Notation}

$A_{c, l}=$ specimen longitudinal cross section

$A_{f}=$ cross section area of the confinement system

$A_{g}=$ area of specimen gross cross section

$A_{s l}=$ cross section area of the longitudinal bars

$\mathrm{CFRP}=$ carbon fiber reinforced polymers

$D=$ diameter of the cylinder cross section

$d_{s t}=$ diameter of the steel hoop

$E_{c i}=$ initial tangent concrete elasticity modulus

$E_{f}=$ CFRP elasticity modulus

$f_{c A}=$ concrete compressive stress at point $\mathrm{A}$

$f_{c c}=$ concrete compressive strength of confined specimen

$f_{c m}=$ average concrete compressive strength

$f_{c o}=$ concrete compressive strength of unconfined specimen

$f_{c o, U R C}=$ concrete compressive strength of unconfined reinforced concrete specimen

$f_{f l}=$ effective lateral confining pressure exerted by CFRP

$f_{l}=$ effective lateral confining pressure

$f_{s l}=$ effective lateral confining pressure exerted by ordinary steel hoops

$H=$ height of the specimen

$k_{1,} k_{2}=$ confinement effectiveness coefficients

$k_{2 R} \quad$ value of $k_{2}$ obtained for $\varepsilon_{f}=0.3 \%$

$L_{k}=$ number of CFRP layers per strip

$s_{f}=$ clear spacing between consecutive FRP strips

$S_{j}=$ number of strips along the specimen

$\mathrm{SG}=$ Strain gauge

$s_{s}=$ clear spacing between steel hoops

$t_{f}=$ thickness of the wet lay-up CFRP sheet

$\mathrm{U}_{\mathrm{cc}}=$ energy dissipated in the softening phase of the confined specimen

$\mathrm{U}_{\mathrm{co}}=$ energy dissipated in the softening phase of the unconfined specimen

$\mathrm{UC}=$ unconfined concrete 


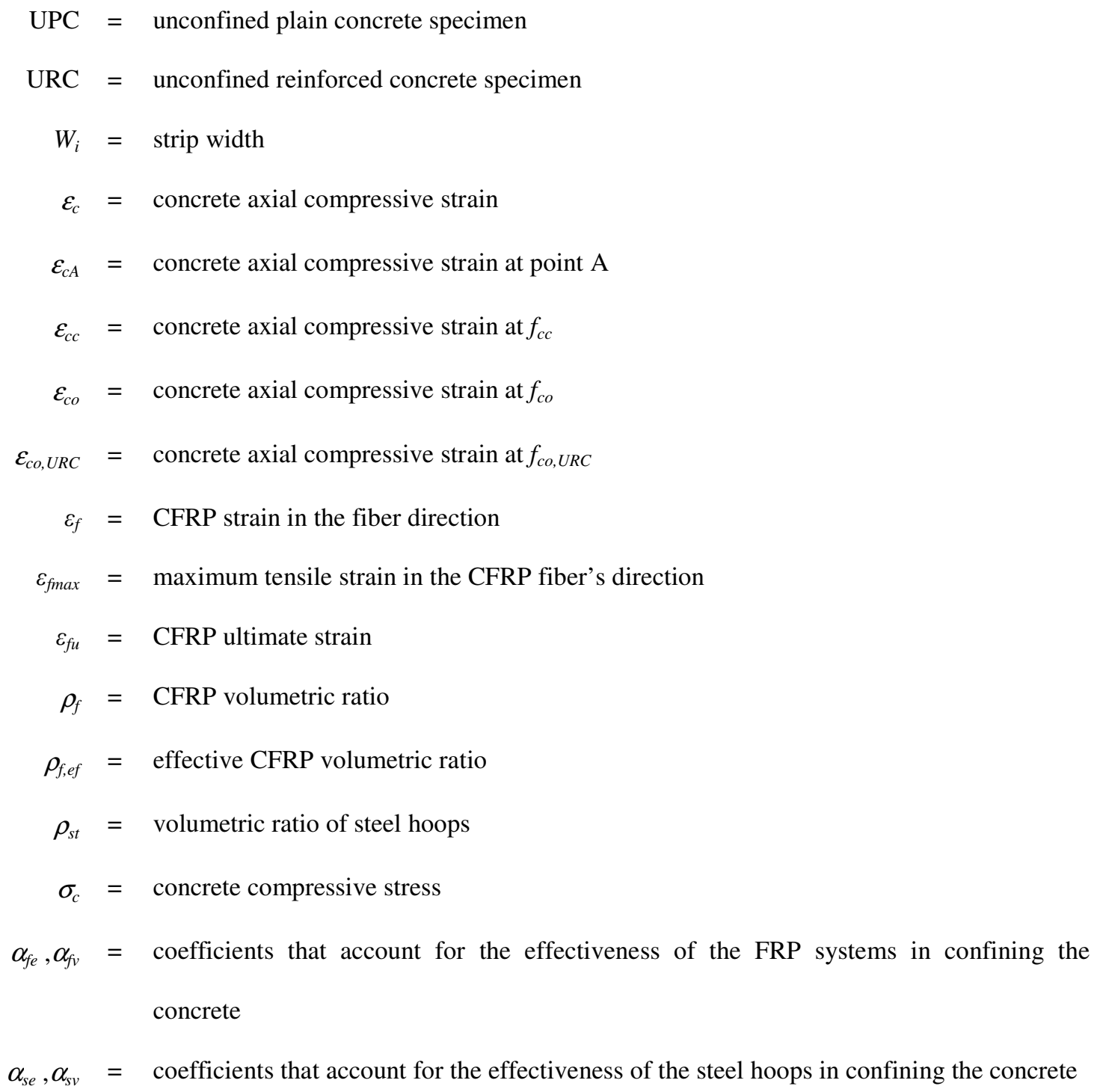


Berthet, J.F., Ferrier, E., and Hamelin, P. (2005). “Compressive behaviour of concrete externally confined by composite jackets.” J. Construction and building materials, Elsevier, vol.19, 223-232.

Bonaldo, E., Barros, J.A.O., and Lourenço, P.J.B. (2005). "Bond characterization between concrete substrate and repairing SFRC using pull-off testing.” International Journal of Adhesion \& Adhesives, vol. 25, 463-474.

CEB-FIP (1990). "Model code.” Thomas Telford, 437 p.

EN 10002-1 (1996). "Metallic materials; tensile testing; part 1": European standards for metalic materials II.

Ferreira, D.R.S.M., and Barros, J.A.O. (2004). "Discrete and full confinement of concrete elements with CFRP sheets." Technical Report, 04-DEC/E-29 Dep. Civil Eng. University of Minho, 165 p. http://www.civil.uminho.pt/composites. (in Portuguese)

Harajli, M. H., Hantouche, E., Soudki, K. (2006). "Stress-strain model for fiber-reinforced polymer jacketed concrete columns.” ACI Structural Journal, 105(5), 672-682.

ISO TC 71/SC 6 N (2003). "Non-conventional reinforcement of concrete-test methods- Part 2: Fiber reinforced polymer (FRP) sheets”. International Organization for Standardization (ISO), Geneva, Switzerland.

Lam, L., and Teng, J. G. (2003). "Design-oriented stress-strain model for FRP-confined concrete." $J$. Construction and Building Materials, Elsevier, vol. 17, 471-489.

Li, Y.-F., Lin, C.T., and Sung, Y.Y. (2003). “A constitutive model for concrete confined with carbon fiber reinforced plastics.” J. Mechanics of Materials, 35, 603-619.

Lin, H.J, and Liao, C.I. (2004). "Compressive strength of reinforced concrete column confined by composite material.” J. Composite Structures, Elsevier, Vol. 65, 239-250.

Mirmiran, A., and Shahawy, M. (1997). "Behavior of concrete columns confined by fiber composites." J. of Structural Engineering, ASCE, 123(5), 583-590.

Mander, J. B., Priestley, M. J. N., and Park, R. (1998). “Theoretical stress-strain model for confined concrete.” J. of structural engineering”, ASCE, 114(8), 1804-1825.

Pessiki, S., Harries, K.A., Kestner, J.T., Sause, R., and Ricles, J. M. (2001). “Axial behaviour of reinforced concrete columns confined with FRP jackets.” J. of composites for construction, ASCE, 5(4), 237- 245.

Samaan, M., Mirmiran, A., and Shahawy, M. (1998). "Model of concrete confined by fiber composites.” J. of Structural Engineering, ASCE, 124(9), 1025-1031.

Spoelstra, M., R., and Monti, G. (1999). "FRP-confined concrete model.” J. of composites for construction, ASCE, 3(3), 143-150. 
Toutanji, H. A. (1999). "Stress-strain characteristics of concrete columns externally confined with advanced fiber composites sheets". Material Journal, ACI, 96(3), 397-404.

Toutanji, H. A., and Deng, Y. (2001). "Strength and durability performance of concrete axially loaded members confined with AFRP composites sheets.” J. of Composites, Elsevier, 255-261.

Xiao, Y., and Wu, H. (2000). “Compressive behavior of concrete confined by carbon fiber composite jackets.” J. of Material in Civil Engineering, ASCE, 125(3), 255-264. 


\section{TABLE CAPTIONS}

Table 1. Experimental program to assess effective confinement arrangements (G1_PC group of tests).

Table 2. G2_PC and G3_RC groups of tests with effective confinement arrangements (see also Fig. 2).

Table 3. CFRP properties (average of five tests).

Table 4. Properties of the steel bars used in the G3_RC group of tests.

Table 5. Values of $f_{c c} / f_{c o}, \varepsilon_{c c} / \varepsilon_{c o}, U_{c c} / U_{c o}$ and $\varepsilon_{\mathrm{fmax}} / \varepsilon_{\mathrm{fu}}$ of the G2_PC group of test series (see also Table 2 and Fig. 5)

Table 6. Main indicators of the efficacy of the confinement systems in the C16S200\$10 and C16S300 10 test series.

Table 7. Main indicators of the efficacy of the confinement systems in the C32S200\$10 and C32S300 110 test series. 
Table 1. Experimental program to assess effective confinement arrangements (G1_PC group of tests).

\begin{tabular}{|c|c|c|c|c|c|}
\hline $\begin{array}{c}\text { Specimen } \\
\text { designation }\end{array}$ & $\begin{array}{c}W \\
{[\mathrm{~mm}]}\end{array}$ & $\begin{array}{c}S \\
{[-]}\end{array}$ & $\begin{array}{c}s_{f} \\
{[\mathrm{~mm}]}\end{array}$ & $\begin{array}{c}L \\
{[\mathrm{~mm}]}\end{array}$ & $\begin{array}{c}\rho_{f} \\
{[\%]}\end{array}$ \\
\hline W15S1L1 & \multirow{15}{*}{15} & \multirow{5}{*}{1} & \multirow{5}{*}{ - } & 1 & 0.02 \\
\hline W15S1L2 & & & & 2 & 0.04 \\
\hline W15S1L3 & & & & 3 & 0.08 \\
\hline W15S1L4 & & & & 4 & 0.10 \\
\hline W15S1L6 & & & & 6 & 0.14 \\
\hline W15S3L1 & & \multirow{5}{*}{3} & \multirow{5}{*}{85} & 1 & 0.08 \\
\hline W15S3L2 & & & & 2 & 0.14 \\
\hline W15S3L3 & & & & 3 & 0.22 \\
\hline W15S3L4 & & & & 4 & 0.28 \\
\hline W15S3L6 & & & & 6 & 0.42 \\
\hline W15S5L1 & & \multirow{5}{*}{5} & \multirow{5}{*}{45} & 1 & 0.12 \\
\hline W15S5L2 & & & & 2 & 0.24 \\
\hline W15S5L3 & & & & 3 & 0.36 \\
\hline W15S5L4 & & & & 4 & 0.46 \\
\hline W15S5L6 & & & & 6 & 0.70 \\
\hline W30S3L3 & \multirow{3}{*}{30} & \multirow{3}{*}{3} & \multirow{3}{*}{70} & 3 & 0.42 \\
\hline W30S3L5 & & & & 5 & 0.70 \\
\hline W30S3L7 & & & & 7 & 0.98 \\
\hline W30S4L3 & \multirow[b]{2}{*}{30} & \multirow[b]{2}{*}{4} & \multirow[b]{2}{*}{45} & 3 & 0.56 \\
\hline W30S4L5 & & & & 5 & 0.94 \\
\hline W45S4L3 & \multirow{3}{*}{45} & \multirow{3}{*}{4} & \multirow{3}{*}{30} & 3 & 0.84 \\
\hline W45S4L5 & & & & 5 & 1.4 \\
\hline W45S4L7 & & & & 7 & 1.98 \\
\hline W60S3L3 & \multirow{3}{*}{60} & \multirow{3}{*}{3} & \multirow{3}{*}{40} & 3 & 0.84 \\
\hline W60S3L5 & & & & 5 & 1.40 \\
\hline W60S3L7 & & & & 7 & 1.98 \\
\hline
\end{tabular}


Table 2. G2_PC and G3_RC groups of tests with effective confinement arrangements (see also Fig. 2).

\begin{tabular}{|c|c|c|c|c|c|c|c|}
\hline \multicolumn{4}{|c|}{ G2_PC: Without steel reinforcement } & \multicolumn{4}{|c|}{ G3_RC: Longitudinal steel bars: $4 \phi 10$; Steel hoops: $\phi 6 / / 120$} \\
\hline & & \multicolumn{2}{|c|}{ Concrete average compressive strength at 28 days } & & & \multicolumn{2}{|c|}{ Concrete average compressive strength at 28 days } \\
\hline & & $16 \mathrm{MPa}$ & $23 \mathrm{MPa}$ & & & $16 \mathrm{MPa}$ & $32 \mathrm{MPa}$ \\
\hline \multirow[t]{2}{*}{$\begin{array}{l}\text { Type of } \\
\text { CFRP sheet }\end{array}$} & \begin{tabular}{|l} 
CF130 S\&P \\
$240\left(300 \mathrm{~g} / \mathrm{m}^{2}\right)$
\end{tabular} & C16S200 & $\mathrm{C} 23 \mathrm{~S} 200$ & \multirow[t]{2}{*}{$\begin{array}{l}\text { Type of CFRP } \\
\text { sheet }\end{array}$} & $\begin{array}{l}\text { CF130 S\&P } 240 \\
\left(300 \mathrm{~g} / \mathrm{m}^{2}\right)\end{array}$ & C16S200ф10 & C32S200ф10 \\
\hline & $\begin{array}{l}\text { CF120 S\&P } \\
240\left(200 \mathrm{~g} / \mathrm{m}^{2}\right)\end{array}$ & $\mathrm{C} 16 \mathrm{~S} 300$ & $\mathrm{C} 23 \mathrm{~S} 300$ & & $\begin{array}{l}\text { CF120 S\&P } 240 \\
\left(200 \mathrm{~g} / \mathrm{m}^{2}\right)\end{array}$ & $\mathrm{C} 16 \mathrm{~S} 300 \phi 10$ & $\mathrm{C} 32 \mathrm{~S} 300 \phi 10$ \\
\hline
\end{tabular}


Table 3. CFRP properties (average of five tests).

\begin{tabular}{lcccc}
\hline \hline CFRP Sheets & Thickness & Tensile strength & Ultimate strain & Modulus of elasticity \\
& $(\mathrm{mm})$ & $(\mathrm{MPa})$ & $(\%)$ & $(\mathrm{GPa})$ \\
\hline CF120 & 0.113 & 3539 & 1.53 & 232 \\
\hline CF130 & 0.176 & 3250 & 1.46 & 230 \\
\hline \hline
\end{tabular}


Table 4. Properties of the steel bars used in the G3_RC group of tests.

\begin{tabular}{ccccc}
\hline \hline $\begin{array}{c}\text { Bar diameter } \\
(\mathrm{mm})\end{array}$ & Yield stress & Tensile strength & Modulus of elasticity & Ultimate strain \\
& $(\mathrm{MPa})$ & $(\mathrm{MPa})$ & $(\mathrm{GPa})$ & 8 \\
\hline 6 & 468.3 & 616.2 & 212.2 & 14 \\
\hline 10 & 421.2 & 539.3 & 196.5 & 8 \\
\hline \hline
\end{tabular}


Table 5. Values of $f_{c c} / f_{c o}, \varepsilon_{c c} / \varepsilon_{c o}, U_{c c} / U_{c o}$ and $\varepsilon_{\mathrm{fmax}} / \varepsilon_{\mathrm{fu}}$ of the G2_PC group of test series (see also Table 2 and Fig. 5)

\begin{tabular}{|c|c|c|c|c|c|c|c|c|c|c|c|c|c|c|c|c|c|c|c|c|}
\hline & \multicolumn{20}{|c|}{ Group } \\
\hline & \multicolumn{5}{|c|}{ C16S200 } & \multicolumn{5}{|c|}{ C16S300 } & \multicolumn{5}{|c|}{ C23S200 } & \multicolumn{5}{|c|}{ C23S300 } \\
\hline & $\begin{array}{c}\rho_{f} \\
(\%)\end{array}$ & $f_{c c} / f_{c o}$ & $\overline{\mathcal{E}_{c c} / \mathcal{E}_{c o}}$ & $U_{c c} / U_{c o}$ & $\varepsilon_{f \max } \varepsilon_{f u}$ & $\begin{array}{c}\rho_{f} \\
(\%)\end{array}$ & $f_{c c} / f_{c o}$ & $\mathcal{E}_{c c} / \varepsilon_{c o}$ & $U_{c c} / U_{c o}$ & $\varepsilon_{f \max } / \varepsilon_{f u}$ & $\begin{array}{c}\rho_{f} \\
(\%)\end{array}$ & $f_{c c} / f_{c o}$ & $\mathcal{E}_{c c} / \mathcal{E}_{c o}$ & $U_{c c} U_{c o}$ & $\varepsilon_{f \max } / \varepsilon_{f u}$ & $\begin{array}{c}\rho_{f} \\
(\%)\end{array}$ & $f_{c c} / f_{c o}$ & $\mathcal{E}_{c c} \mathcal{E}_{c o}$ & $U_{c c} / U_{c o}$ & $\varepsilon_{f \max } / \varepsilon_{f u}$ \\
\hline \multirow{2}{*}{ W45S4L3 } & \multirow{2}{*}{0.54} & \multirow{2}{*}{1.66} & \multirow{2}{*}{5.07} & \multirow{2}{*}{3.15} & 0.48 & \multirow{2}{*}{0.85} & \multirow{2}{*}{3.17} & \multirow{2}{*}{12.21} & \multirow{2}{*}{35.42} & - & \multirow{2}{*}{0.54} & \multirow{2}{*}{1.37} & \multirow{2}{*}{3.14} & \multirow{2}{*}{3.84} & 0.41 & \multirow{2}{*}{0.85} & \multirow{2}{*}{1.84} & \multirow{2}{*}{7.24} & \multirow{2}{*}{10.46} & 0.18 \\
\hline & & & & & 0.53 & & & & & & & & & & 0.46 & & & & & 0.48 \\
\hline \multirow{2}{*}{ W45S4L5 } & \multirow{2}{*}{0.90} & \multirow{2}{*}{2.09} & \multirow{2}{*}{7.20} & \multirow{2}{*}{7.35} & 0.44 & \multirow{2}{*}{1.41} & \multirow{2}{*}{3.96} & \multirow{2}{*}{16.00} & \multirow{2}{*}{47.64} & 0.52 & \multirow{2}{*}{0.90} & \multirow{2}{*}{1.81} & & & 0.51 & & & & & 0.42 \\
\hline & & & & & 0.53 & & & & & 0.69 & & & 4.55 & 7.58 & 0.44 & 1.41 & 2.33 & 8.45 & 21.90 & 0.43 \\
\hline W60S3L3 & 0.54 & 1.64 & 5.46 & 3.27 & 0.42 & 0.85 & 2.62 & 12.15 & 31.05 & 0.70 & 0.54 & 1.38 & 3.21 & 3.95 & 0.52 & 0.85 & 1.65 & 8.32 & 15.98 & 0.73 \\
\hline W60S3L5 & 0.90 & 2.08 & 8.48 & 12.67 & 0.55 & 1.41 & 3.51 & 20.08 & 43.18 & 0.59 & 0.90 & 1.60 & 4.22 & 7.58 & 0.51 & 1.41 & 1.98 & 8.36 & 18.40 & 0.41 \\
\hline W300S1L3 & 0.90 & 2.44 & 8.92 & 11.57 & 0.61 & 1.41 & 4.23 & 12.26 & 43.65 & 0.54 & 0.90 & 1.93 & 5.02 & 7.70 & 0.62 & 1.41 & 2.76 & 7.45 & 14.25 & 0.63 \\
\hline W300S1L5 & 1.51 & 3.41 & 11.24 & 13.81 & 0.85 & 2.35 & 6.58 & 16.54 & 64.99 & 0.66 & 1.51 & 2.36 & 5.89 & 8.56 & 0.51 & 2.35 & $3.22^{*}$ & $8.77^{*}$ & $31.11^{*}$ & $0.51^{*}$ \\
\hline
\end{tabular}


Table 6. Main indicators of the efficacy of the confinement systems in the C16S200 $\phi 10$ and C16S300 110 test series.

\begin{tabular}{|c|c|c|c|c|c|c|c|c|c|}
\hline $\begin{array}{c}\text { Type of } \\
\text { sheet }\end{array}$ & $\begin{array}{c}\text { Specimen } \\
\text { designation }\end{array}$ & $L$ & $\begin{array}{c}\rho_{f} \\
(\%)\end{array}$ & $\begin{array}{c}f_{c c} \\
(\mathrm{MPa})\end{array}$ & $\begin{array}{l}\mathcal{E}_{c c} \\
(\%)\end{array}$ & $\overline{\mid f_{c c} / f_{c o, U R C}}$ & $\mathcal{E}_{c c} / \mathcal{E}_{c o, U R C}$ & $\begin{array}{l}\varepsilon_{\text {fmax }} \\
(\%)\end{array}$ & $\varepsilon_{f \max } / \varepsilon_{f u}$ \\
\hline & $\begin{array}{c}\text { Unconf. plain } \\
\text { concrete (UPC) }\end{array}$ & & & $\begin{array}{c}13.87 \\
\left(f_{c o, U P C}\right)\end{array}$ & $\begin{array}{c}0.271 \\
\left(\varepsilon_{c o, U P C}\right)\end{array}$ & - & - & - & - \\
\hline & $\begin{array}{c}\text { Unconf. } \\
\phi 10 \text { Reinf. Conc. } \\
\text { (URC) }\end{array}$ & & & $\begin{array}{c}15.52 \\
\left(f_{c o, U R C}\right)\end{array}$ & $\begin{array}{c}0.333 \\
\left(\varepsilon_{c o, U R C}\right)\end{array}$ & - & - & - & - \\
\hline S200 & \multirow{2}{*}{ W45L3 } & \multirow{2}{*}{3} & 0.25 & 27.04 & 0.201 & 1.74 & 6.36 & 0.924 & 0.60 \\
\hline S300 & & & 0.40 & 30.96 & 0.284 & 1.99 & 8.48 & 0.965 & 0.62 \\
\hline S200 & \multirow{2}{*}{ W45L5 } & \multirow{2}{*}{5} & 0.42 & 32.89 & 0.3179 & 2.12 & 9.70 & 0.717 & 0.46 \\
\hline S300 & & & 0.66 & 38.23 & 0.400 & 2.46 & 14.85 & 0.7 .84 & 0.51 \\
\hline S200 & \multirow{2}{*}{ W60L3 } & \multirow[b]{2}{*}{3} & 0.34 & 32.92 & 0.261 & 2.12 & 7.88 & 0.901 & 0.58 \\
\hline S300 & & & 0.53 & 36.95 & 0.323 & 2.38 & 9.70 & 0.131 & 0.85 \\
\hline S200 & \multirow{2}{*}{ W60L5 } & \multirow{2}{*}{5} & 0.57 & 43.81 & 0.4049 & 2.82 & 12.12 & 0.989 & 0.64 \\
\hline S300 & & & 0.88 & 46.29 & 0.40 .32 & 2.98 & 16.06 & 0.967 & 0.62 \\
\hline S200 & \multirow{2}{*}{ W600L3 } & \multirow{2}{*}{3} & 0.68 & 46.88 & 0.296 & 3.02 & 9.09 & 0.783 & 0.51 \\
\hline S300 & & & 1.06 & 62.70 & 0.425 & 4.04 & 13.64 & 0.887 & 0.57 \\
\hline S200 & \multirow{2}{*}{ W600L5 } & \multirow{2}{*}{5} & 1.13 & 56.38 & 0.344 & 3.63 & 10.30 & 0.675 & 0.44 \\
\hline S300 & & & 1.76 & 75.12 & 0.480 & 4.84 & 14.55 & 0.112 & 0.72 \\
\hline
\end{tabular}


Table 7. Main indicators of the efficacy of the confinement systems in the C32S200\$10 and C32S300 110 test series.

\begin{tabular}{|c|c|c|c|c|c|c|c|c|c|}
\hline $\begin{array}{c}\text { Type of } \\
\text { sheet }\end{array}$ & $\begin{array}{c}\text { Specimen } \\
\text { designation }\end{array}$ & $L$ & $\begin{array}{c}\rho_{f} \\
(\%)\end{array}$ & $\begin{array}{c}f_{c c} \\
(\mathrm{MPa})\end{array}$ & $\begin{array}{l}\mathcal{E}_{c c} \\
(\%)\end{array}$ & 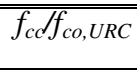 & $\mathcal{E}_{c c} / \mathcal{E}_{c o, U R C}$ & $\begin{array}{l}\mathcal{E}_{\text {fmax }} \\
(\%)\end{array}$ & $\varepsilon_{f \max } / \varepsilon_{f u}$ \\
\hline & $\begin{array}{c}\text { Unconf. plain } \\
\text { concrete (UPC) }\end{array}$ & & & $\begin{array}{c}30.31 \\
\left(f_{c o, U P C}\right) \\
\end{array}$ & $\begin{array}{c}0.312 \\
\left(\varepsilon_{c o, U P C}\right)\end{array}$ & - & - & - & - \\
\hline & $\begin{array}{c}\text { Unconf. } \\
\phi 10 \text { Reinf. Conc. } \\
\text { (URC) }\end{array}$ & & & $\begin{array}{c}33.99 \\
\left(f_{c o, U R C}\right)\end{array}$ & $\begin{array}{c}0.433 \\
\left(\varepsilon_{c o, U R C}\right)\end{array}$ & - & - & - & - \\
\hline S200 & \multirow{2}{*}{ W45L3 } & \multirow{2}{*}{3} & 0.25 & 43.45 & 0.979 & 1.28 & 2.28 & 0.609 & 0.39 \\
\hline S300 & & & 0.40 & 46.11 & 0.137 & 1.38 & 3.21 & 0.797 & 0.51 \\
\hline S200 & \multirow{2}{*}{ W45L5 } & \multirow{2}{*}{5} & 0.42 & 49.10 & 0.121 & 1.47 & 2.81 & 0.627 & 0.40 \\
\hline S300 & & & 0.66 & 54.34 & 0.1778 & 1.63 & 4.12 & 0.106 & 0.65 \\
\hline S200 & \multirow[b]{2}{*}{ W60L3 } & \multirow[b]{2}{*}{3} & 0.34 & 47.91 & 0.115 & 1.43 & 2.67 & 0.837 & 0.54 \\
\hline S300 & & & 0.53 & 55.93 & 0.150 & 1.67 & 3.49 & 0.125 & 0.81 \\
\hline S200 & \multirow{2}{*}{ W60L5 } & \multirow{2}{*}{5} & 0.57 & 51.18 & 0.150 & 1.53 & 3.51 & 0.590 & 0.38 \\
\hline S300 & & & 0.88 & 64.38 & 0.216 & 1.93 & 5.02 & 0.987 & 0.63 \\
\hline S200 & \multirow[b]{2}{*}{ W600L3 } & \multirow[b]{2}{*}{3} & 0.68 & 71.51 & 0.179 & 2.14 & 4.16 & 0.689 & 0.44 \\
\hline S300* & & & 1.06 & $\begin{array}{c}71.99 * \\
{[96.09]^{* *}}\end{array}$ & $0.125^{*}$ & $\begin{array}{c}2.16 \\
{[2.83]^{* *}}\end{array}$ & $2.93 *$ & $0.544 *$ & $0.35^{*}$ \\
\hline S200* & \multirow[b]{2}{*}{ W600L5 } & \multirow[b]{2}{*}{5} & 1.14 & $\begin{array}{c}71.68^{*} \\
{[100.31]^{* *}}\end{array}$ & $0.114^{*}$ & $\begin{array}{c}2.15 \\
{[2.95]^{* *}}\end{array}$ & $2.65^{*}$ & $0.387 *$ & $0.25^{*}$ \\
\hline S300* & & & 1.76 & $\begin{array}{c}\text { 71.43* } \\
{[111.12]^{* *}}\end{array}$ & $0.131 *$ & $\begin{array}{c}2.14 \\
{[3.27]^{* *}}\end{array}$ & $3.05^{*}$ & $0.324 *$ & $0.21 *$ \\
\hline
\end{tabular}

* Values recorded when the load carrying capacity of the equipment was attained, without the occurrence of the failure of the specimens

** Values at the failure of the specimens 


\section{FIGURE CAPTIONS}

Fig. 1. Confinement arrangements of G1_PC group of tests.

Fig. 2. Confinement arrangements of: (a) G2_PC and (b) G3_RC group of tests.

Fig. 3. Results of the G1_PC group of tests (see also Table 1 and Fig. 1).

Fig. 4. Results of the G2_PC test series: (a) W45; (b) W60; (c) W300 (see Table 2).

Fig. 5. Typical compressive stress-strain diagrams for unconfined and FRP-confined concrete specimens.

Fig. 6. Influence of concrete strength on G3_RC group of test series: (a) W45; (b) W60; (c) W600.

Fig. 7. Influence of CFRP stiffness on G3_RC group of test series: (a1) W45 of C16; (a2) W60 of C16; (a3) W600 of C16; (b1) W45 of C32; (b2) W60 of C32; (b3) W600 of C32.

Fig. 8. Influence of confinement arrangement type on G3_RC group of test series: (a) C16S200ф10; (b) C16S300ф10; (c) C32S200ф10; (d) C32S300ф10.

Fig. 9. Schematic representation of the stress-strain approach for FRP confined concrete.

Fig. 10. Variation of confinement parameter $k_{1}$ with lateral confining pressure for: (a) C16 and (b) C32 series of tests.

Fig. 11. Variation of confinement parameter $k_{2}$ with lateral strain.

Fig.12. Comparison between analytical model and experimental results for: (a) C16S200ф10; (b) C16S300\$10; (c) C32S200ф10; (d) C32S300ф10. 


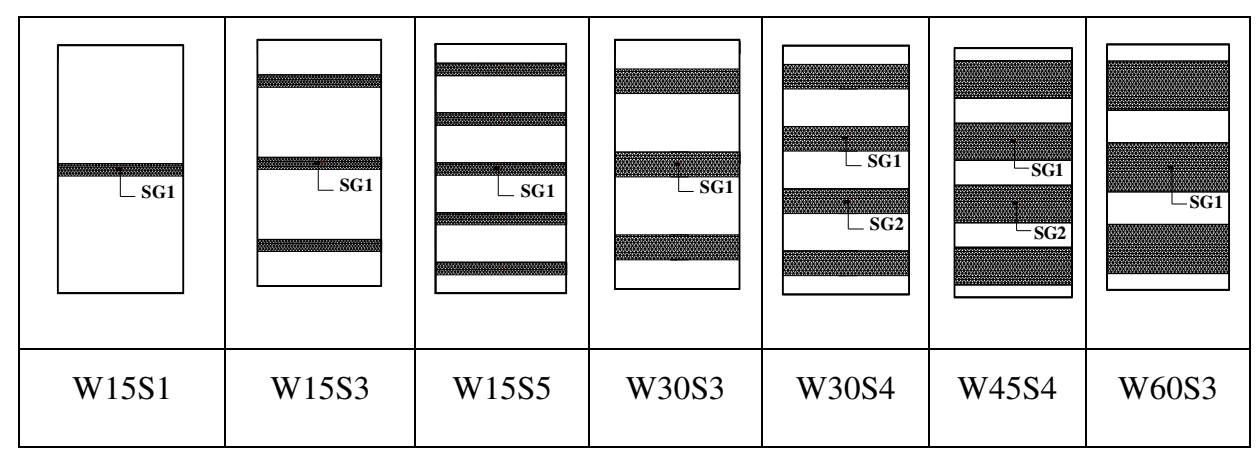

Fig. 1. Confinement arrangements of G1_PC group of tests. 


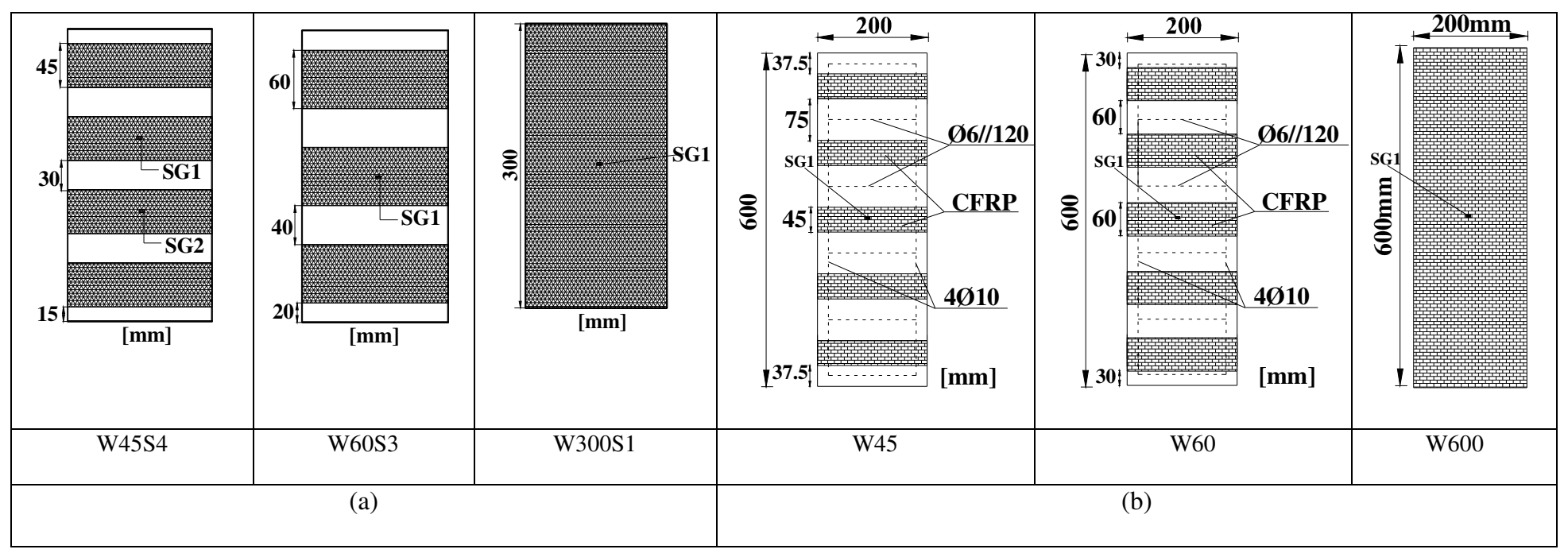

Fig. 2. Confinement arrangements of: (a) G2_PC and (b) G3_RC group of tests. 


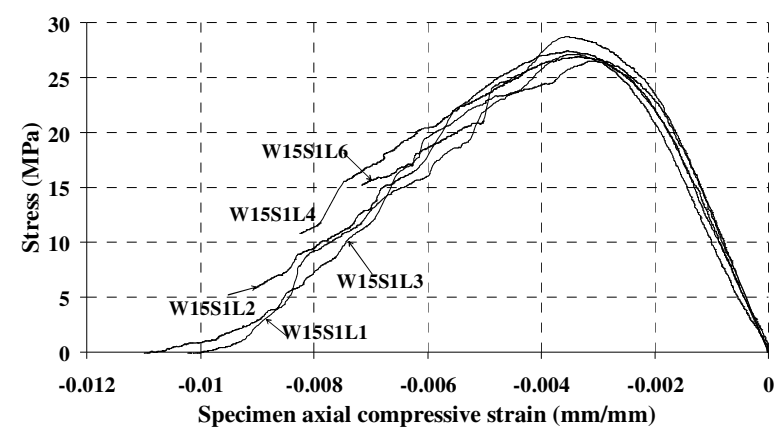

(a)

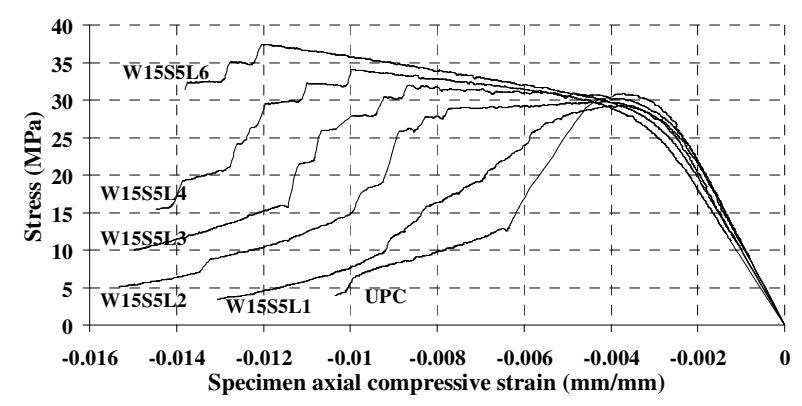

(c)

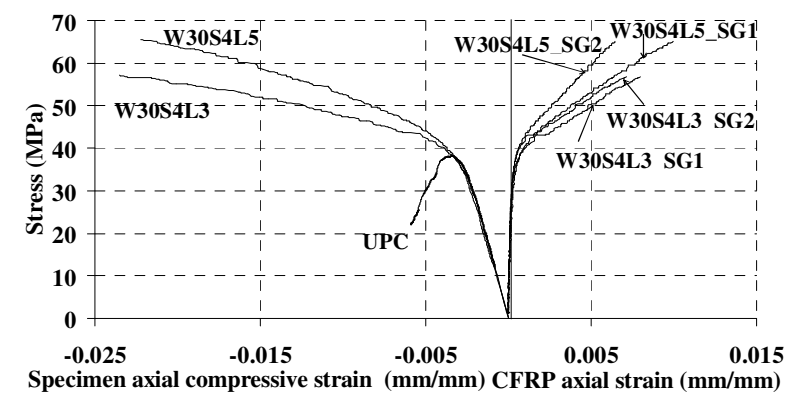

(e)

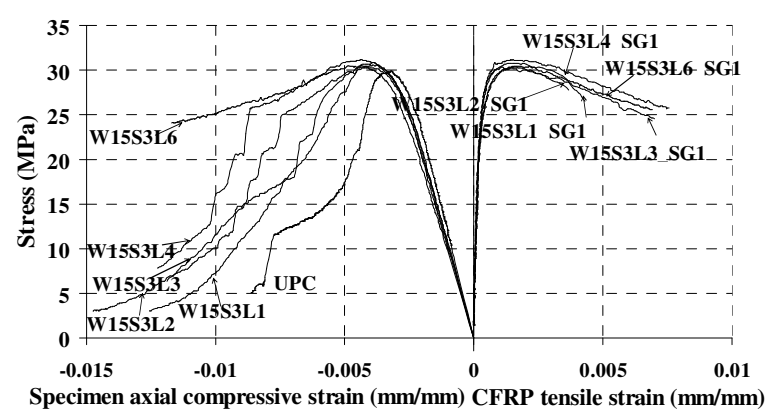

(b)

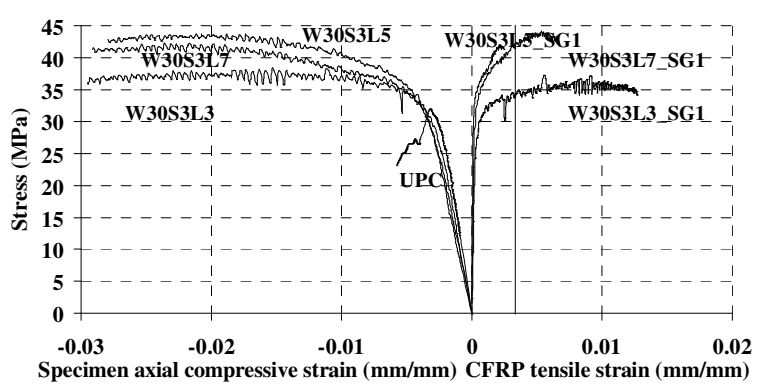

(d)

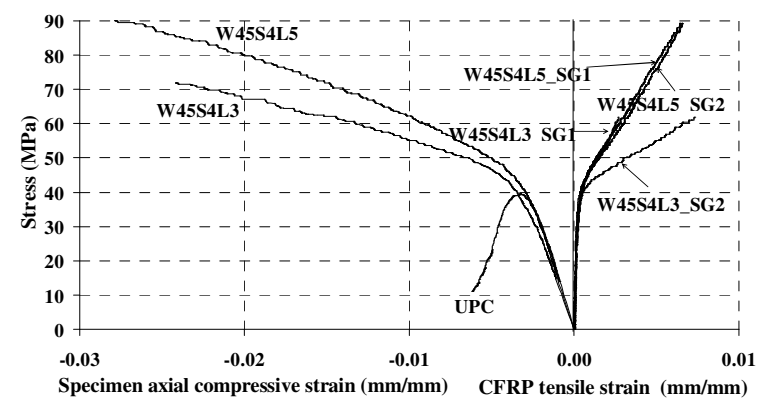

(f)

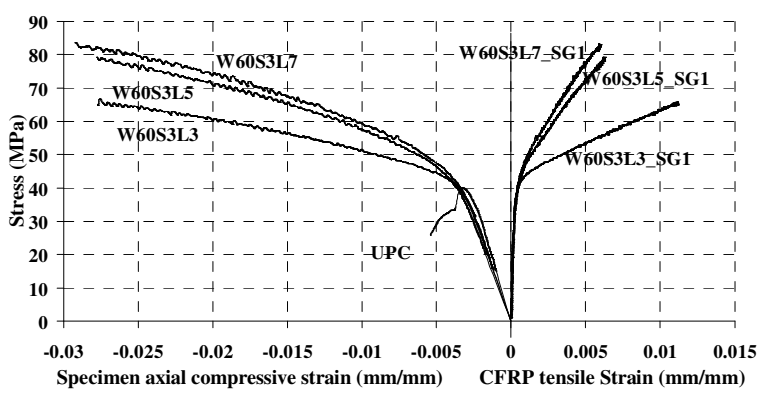

(g)

Fig. 3. Results of the G1_PC group of tests (see also Table 1 and Fig. 1). 


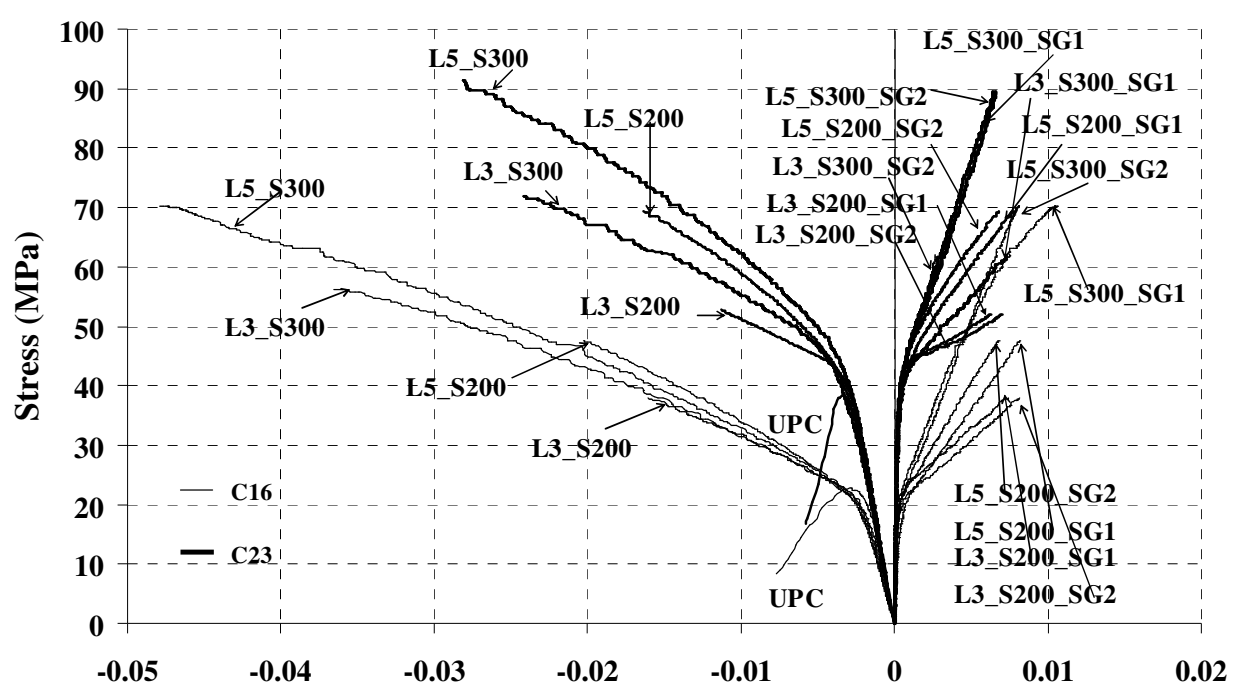

(a)

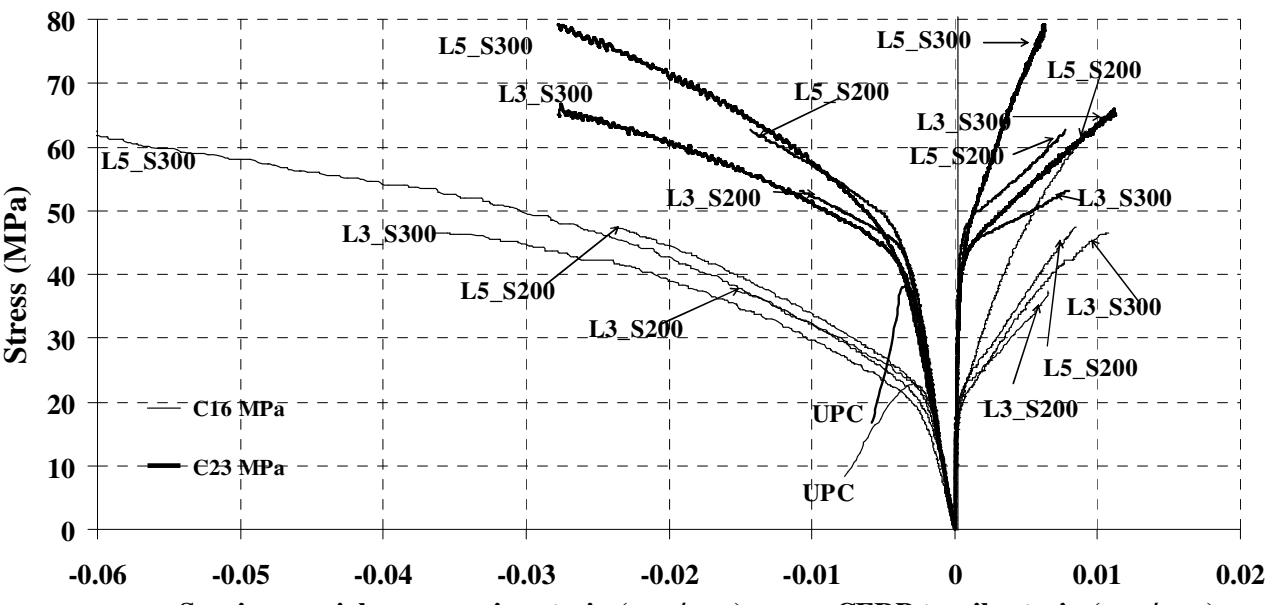

(b)

Specimen axial compressive strain $(\mathrm{mm} / \mathrm{mm})$

CFRP tensile strain $(\mathbf{m m} / \mathbf{m m})$

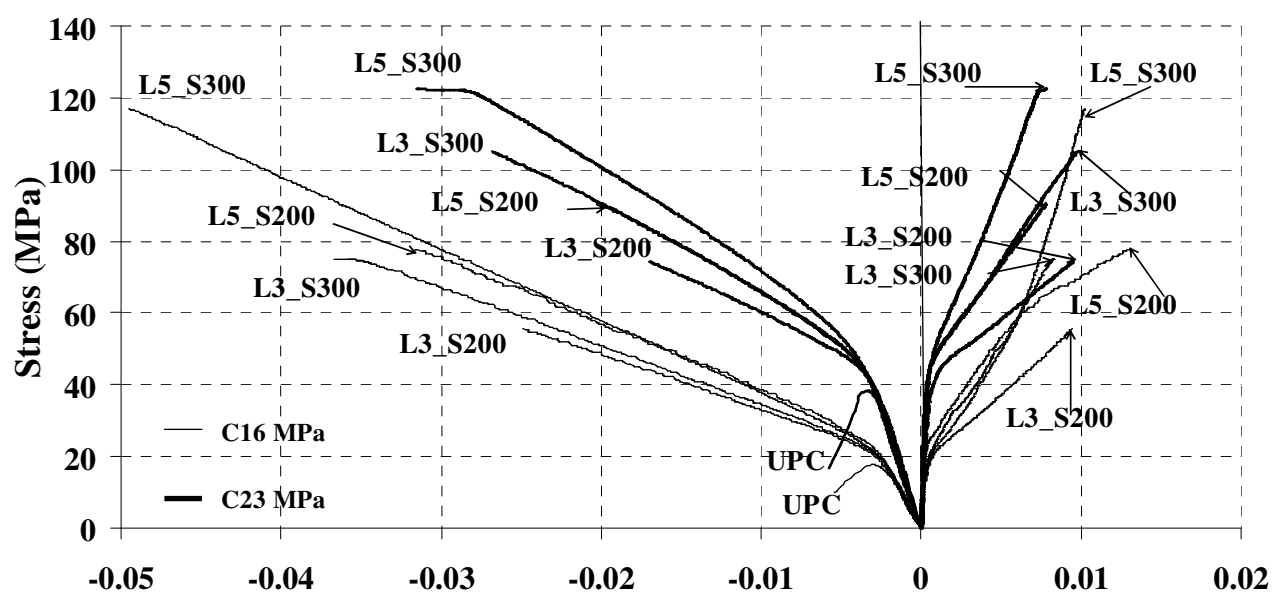

(c) Specimen axial compressive strain $(\mathrm{mm} / \mathrm{mm}) \quad$ CFRP tensile strain $(\mathrm{mm} / \mathrm{mm})$

Fig. 4. Results of the G2_PC test series: (a) W45; (b) W60; (c) W300 (see Table 2). 


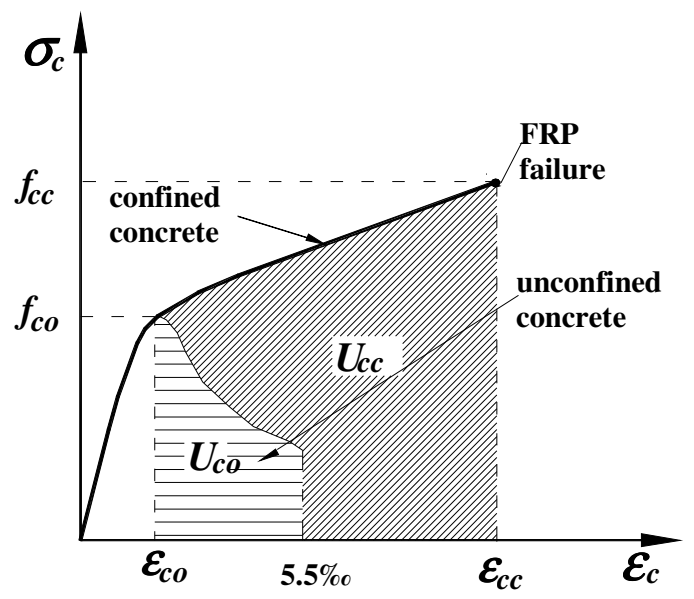

Fig. 5. Typical compressive stress-strain diagrams for unconfined and FRP-confined concrete specimens. 


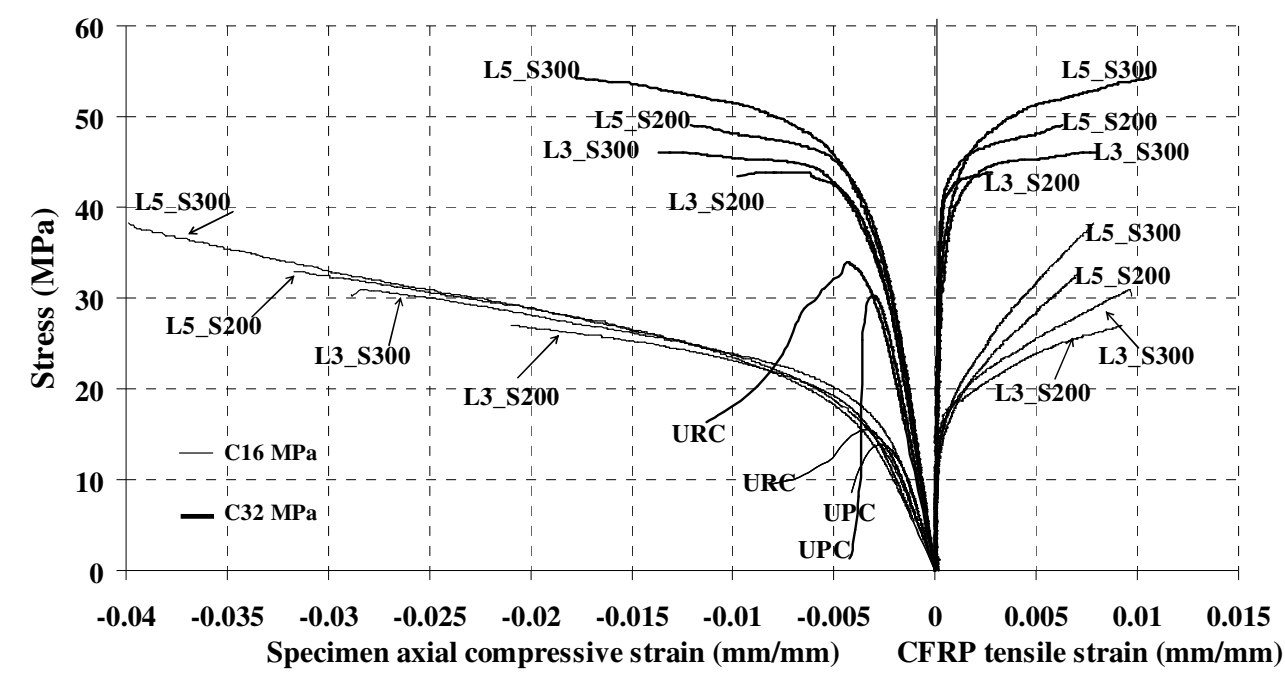

(a)

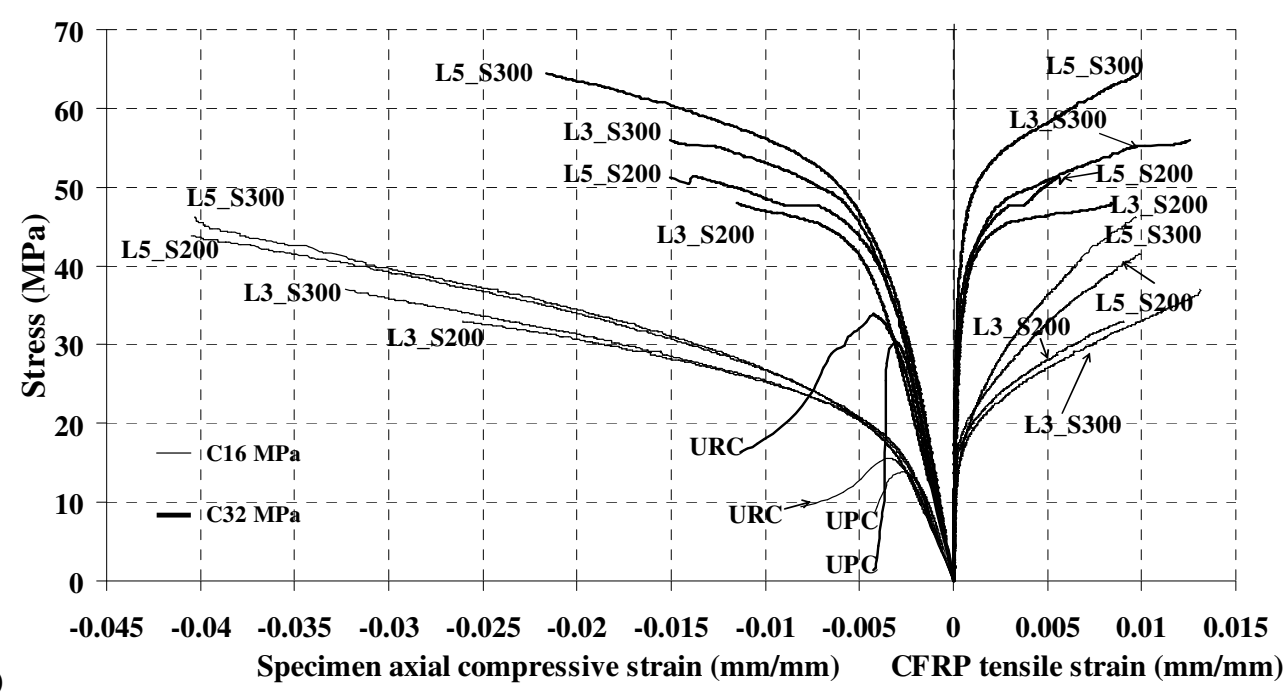

(b)

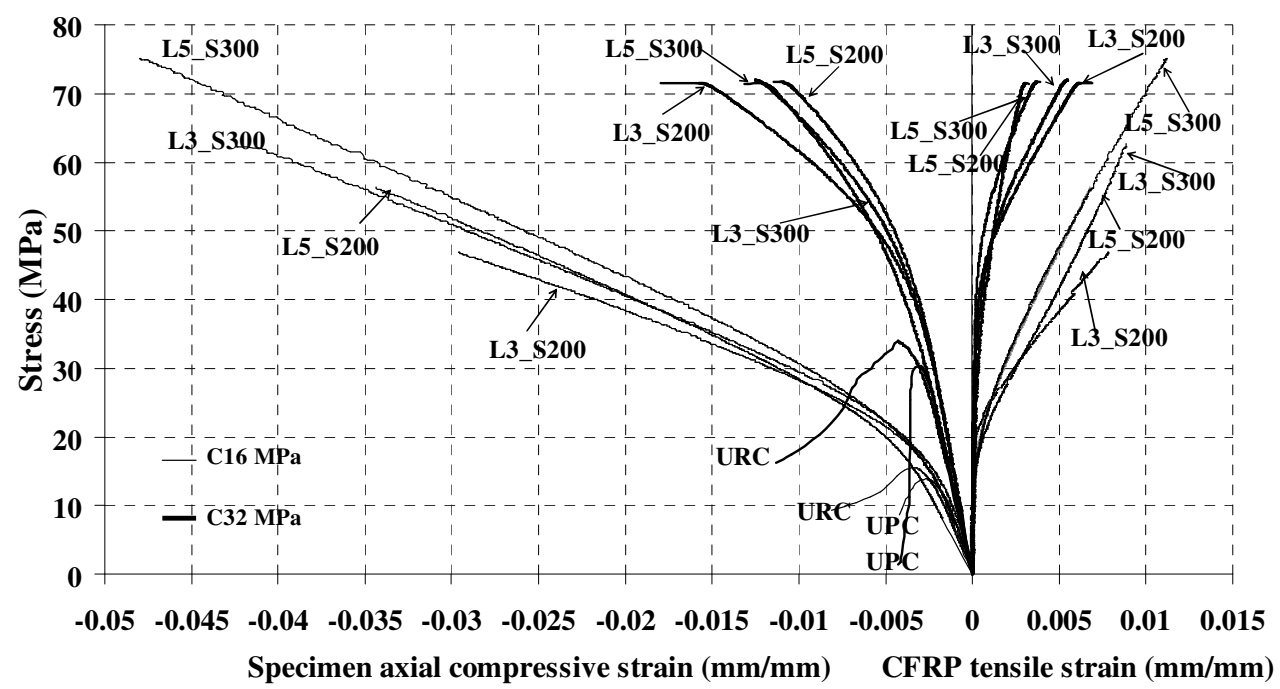

Fig. 6. Influence of concrete strength on G3_RC group of test series: (a) W45; (b) W60; (c) W600. 


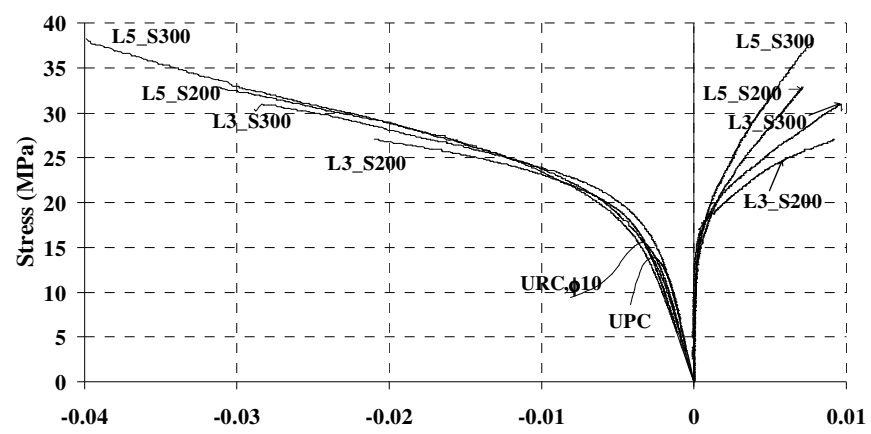

Specimen axial compressive strain $(\mathbf{m m} / \mathbf{m m})$ CFRP tensile strain $(\mathbf{m m} / \mathbf{m m})$

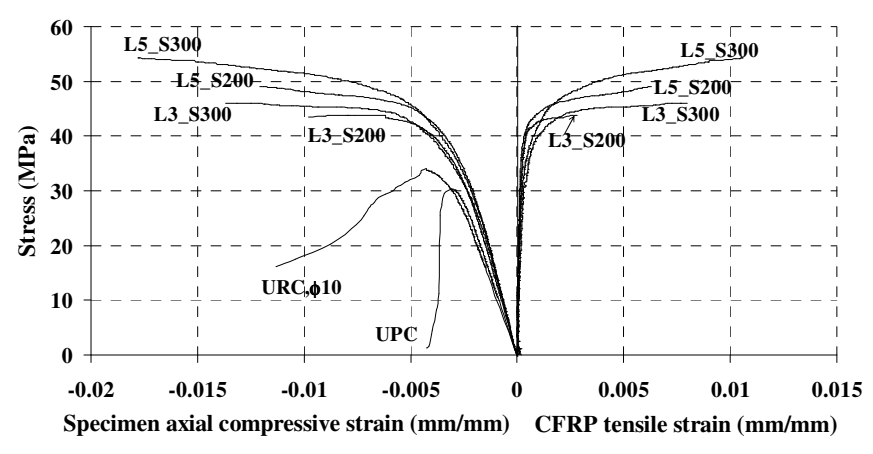

(b1)

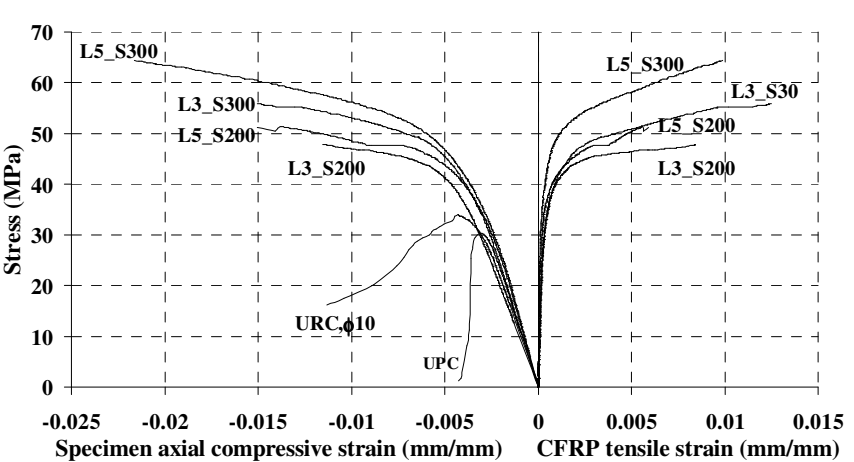

(b2)

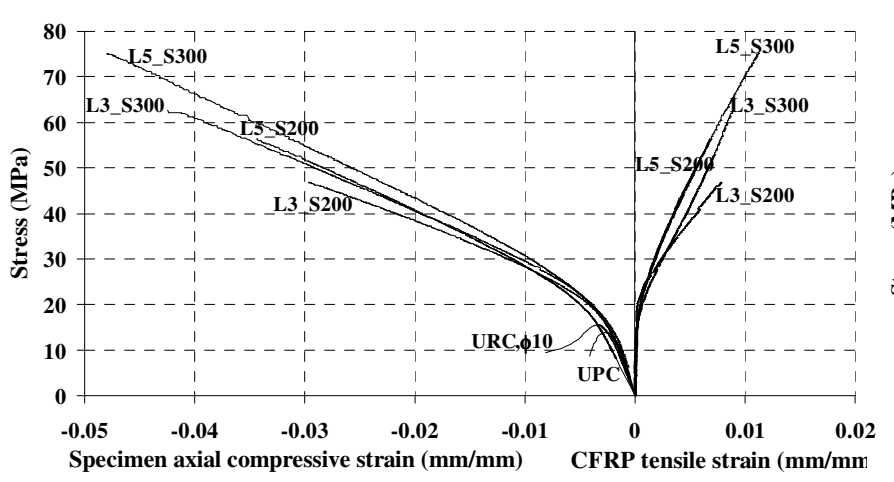

(a3)

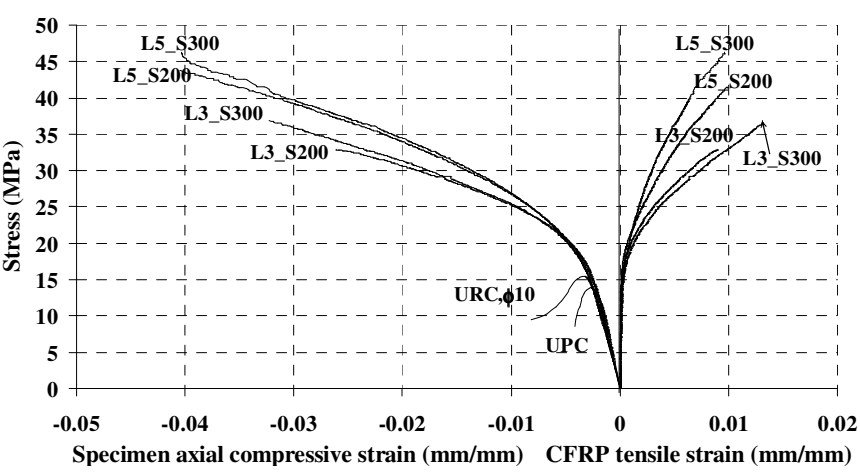

(a2)

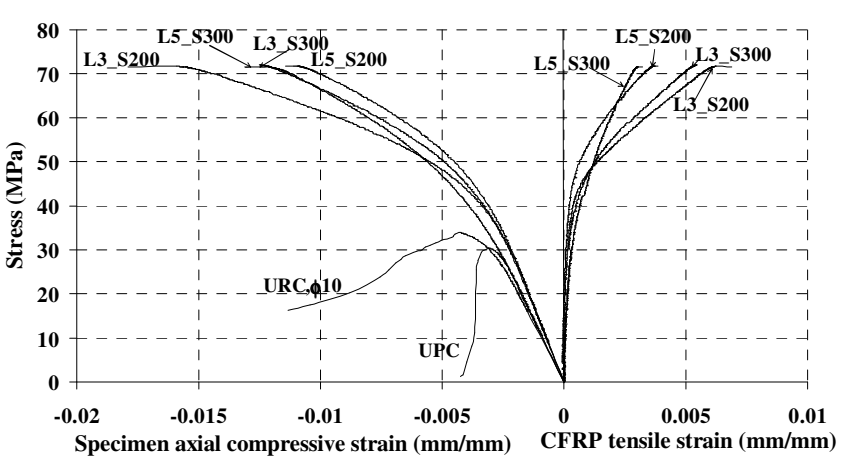

(b3)

Fig. 7. Influence of CFRP stiffness on G3_RC group of test series: (a1) W45 of C16; (a2) W60 of C16; (a3) W600 of C16; (b1) W45 of C32; (b2) W60 of C32; (b3) W600 of C32. 


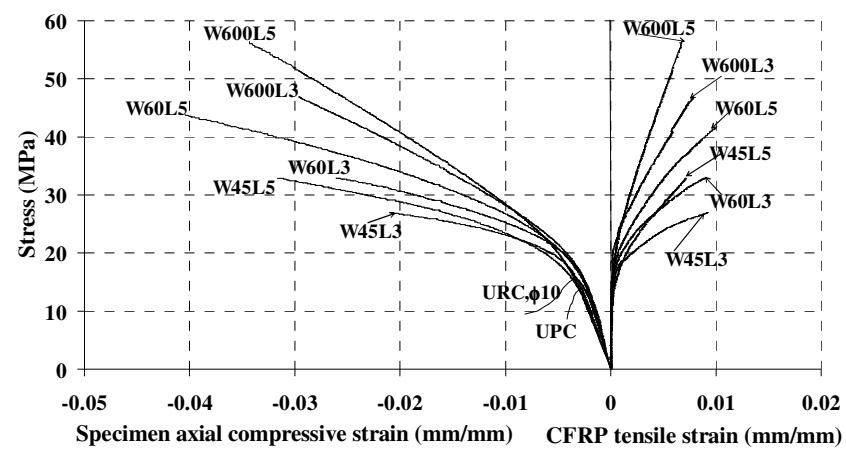

(a)

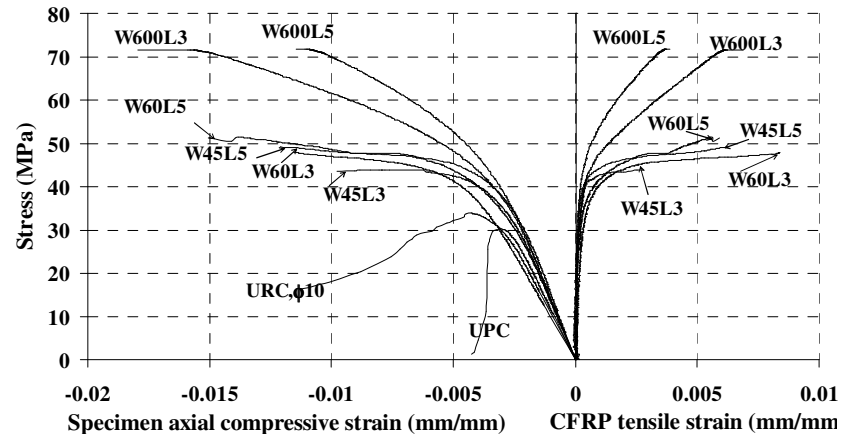

(c)

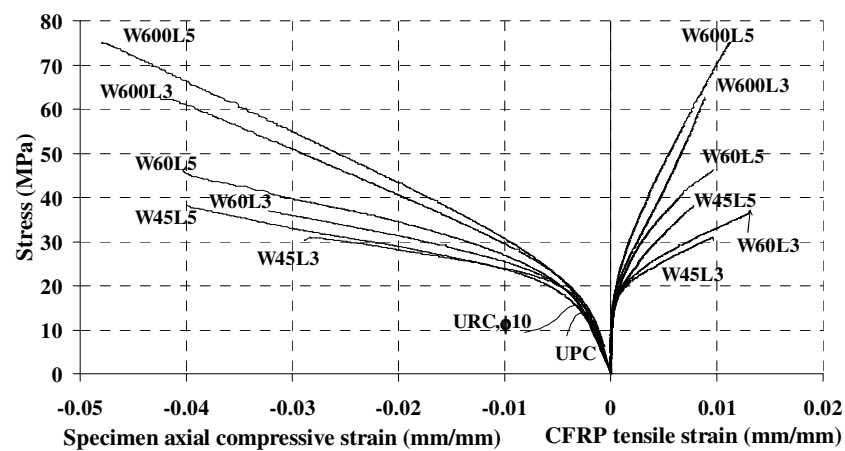

(b)

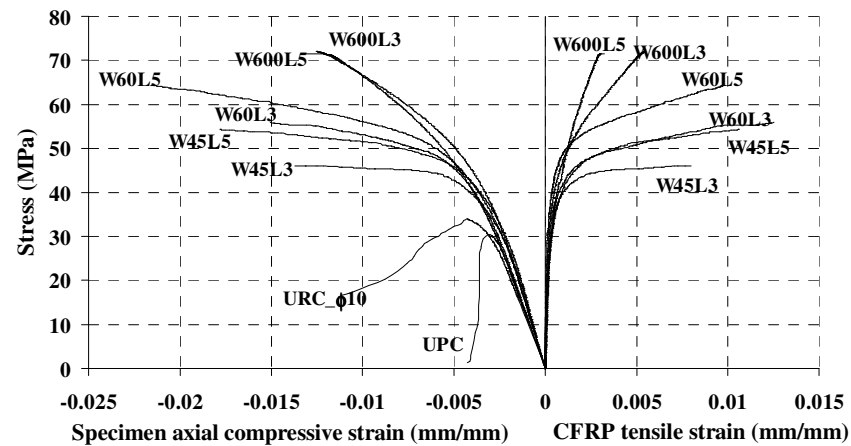

(d)

Fig. 8. Influence of confinement arrangement type on G3_RC group of test series: (a) C16S200ф10; (b) C16S300\$10;

(c) C32S200ф10; (d) C32S300ф10. 


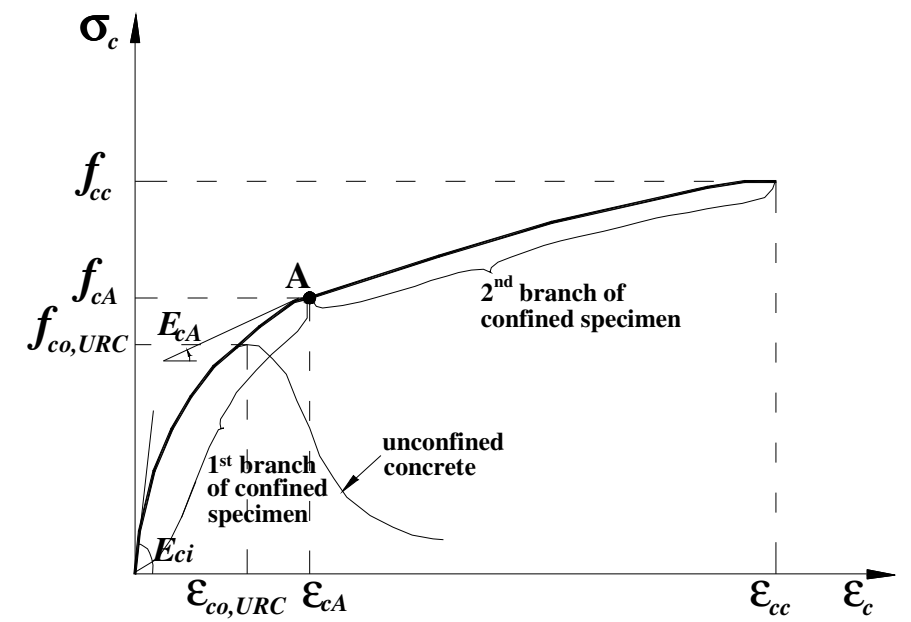

Fig. 9. Schematic representation of the stress-strain approach for FRP confined concrete. 


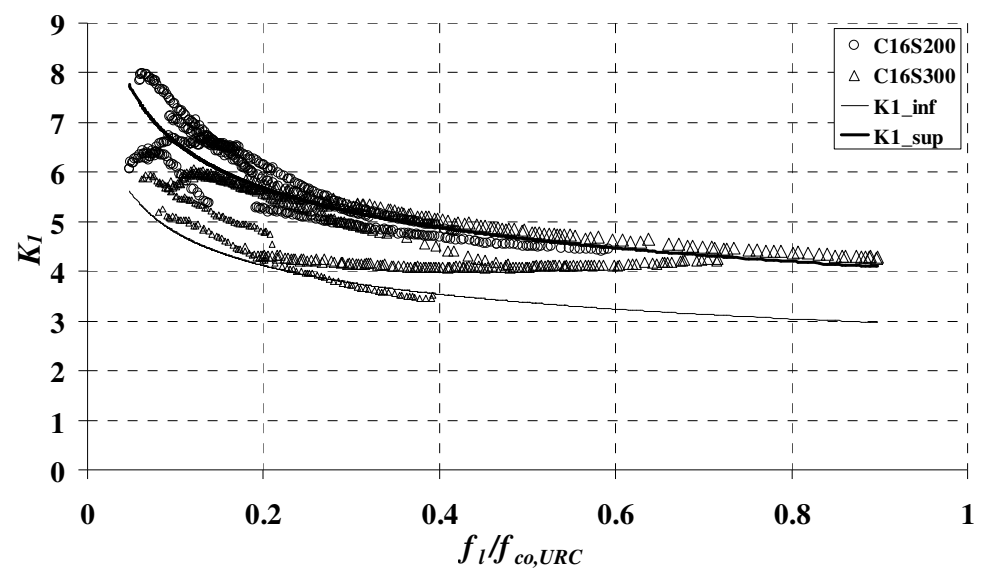

(a)

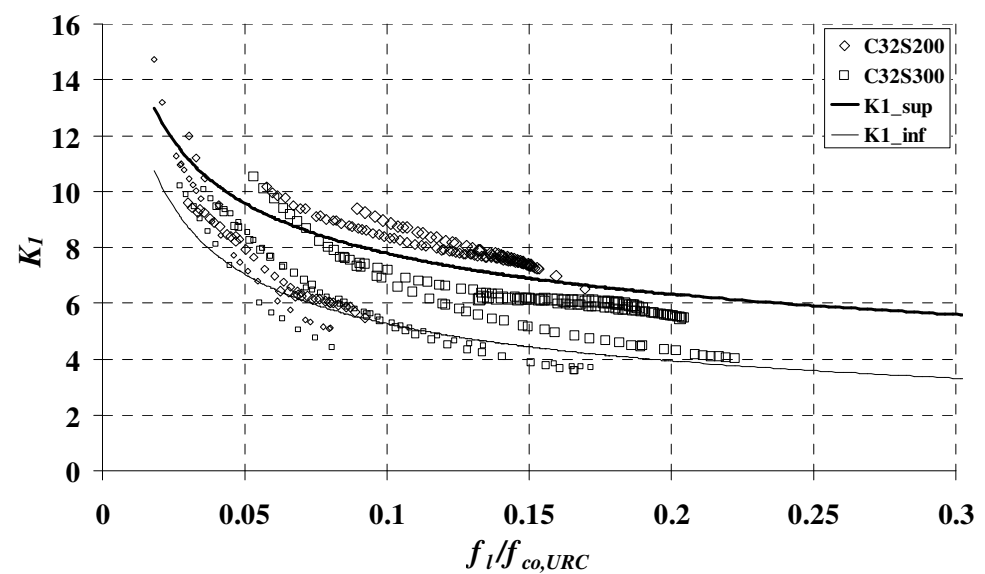

(b)

Fig. 10. Variation of confinement parameter $k_{1}$ with lateral confining pressure for: (a) C16 and (b) C32 series of tests. 


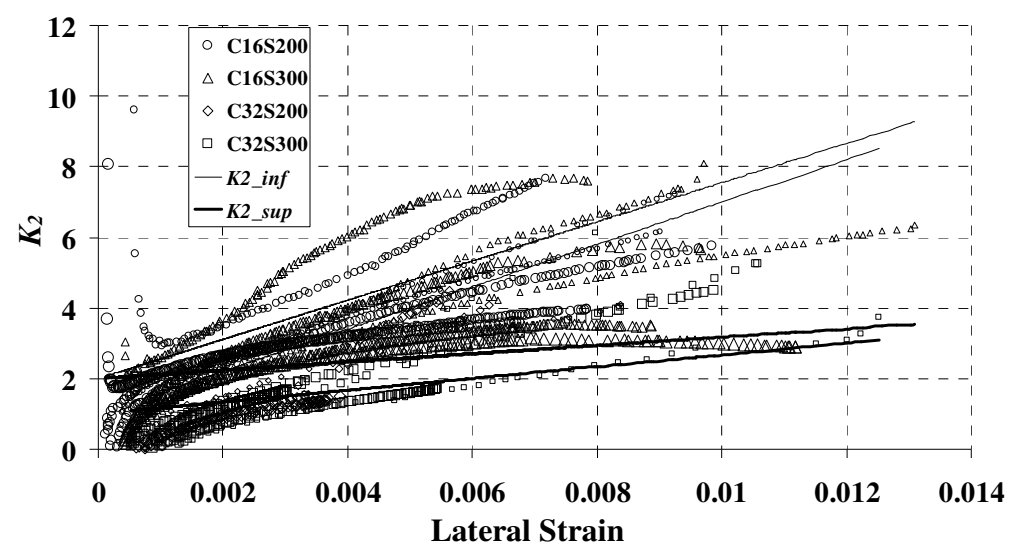

Fig. 11. Variation of confinement parameter $k_{2}$ with lateral strain. 


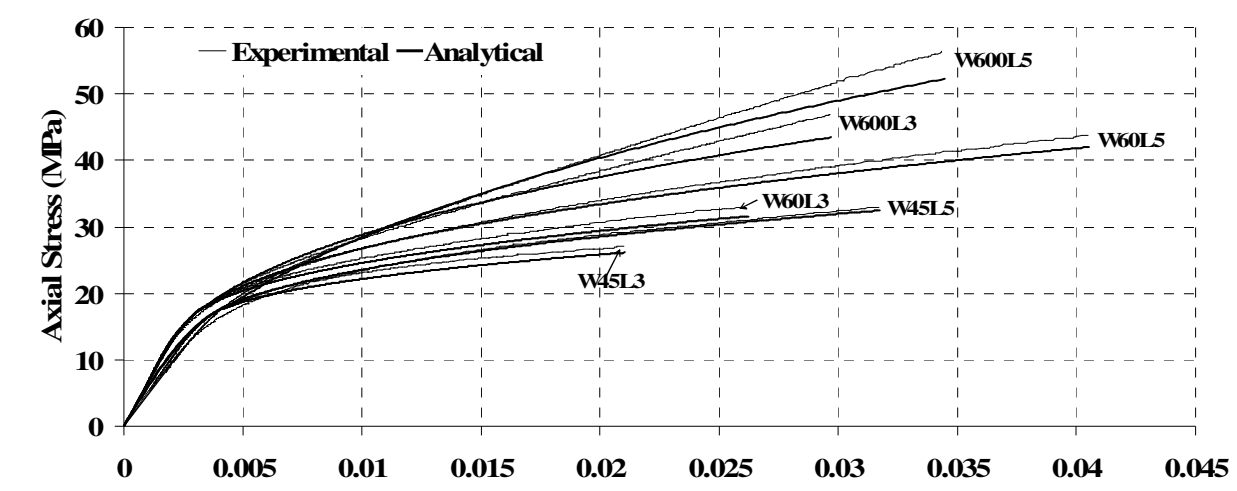

(a)

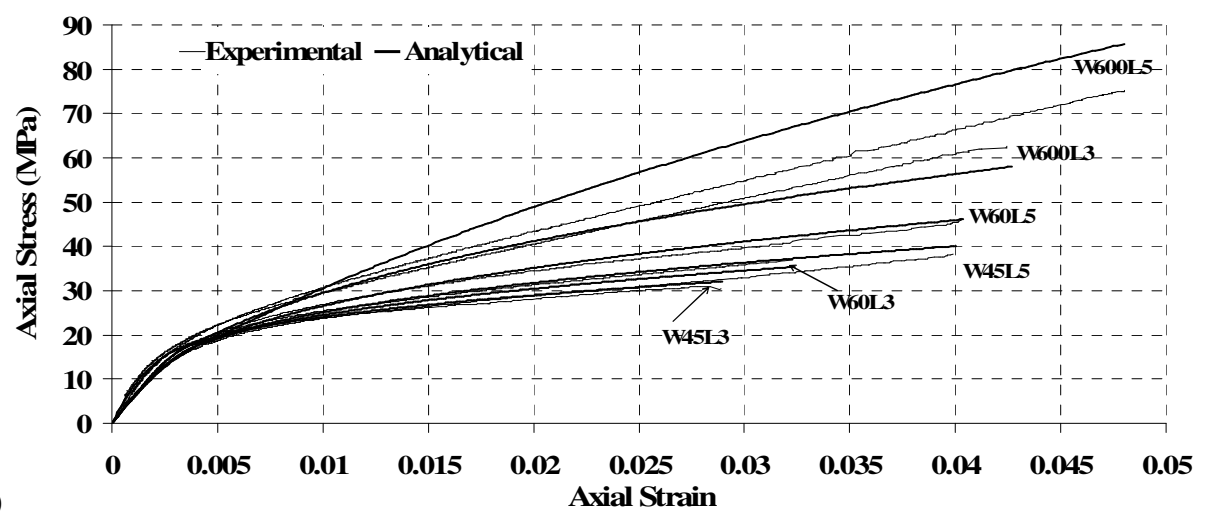

(b)

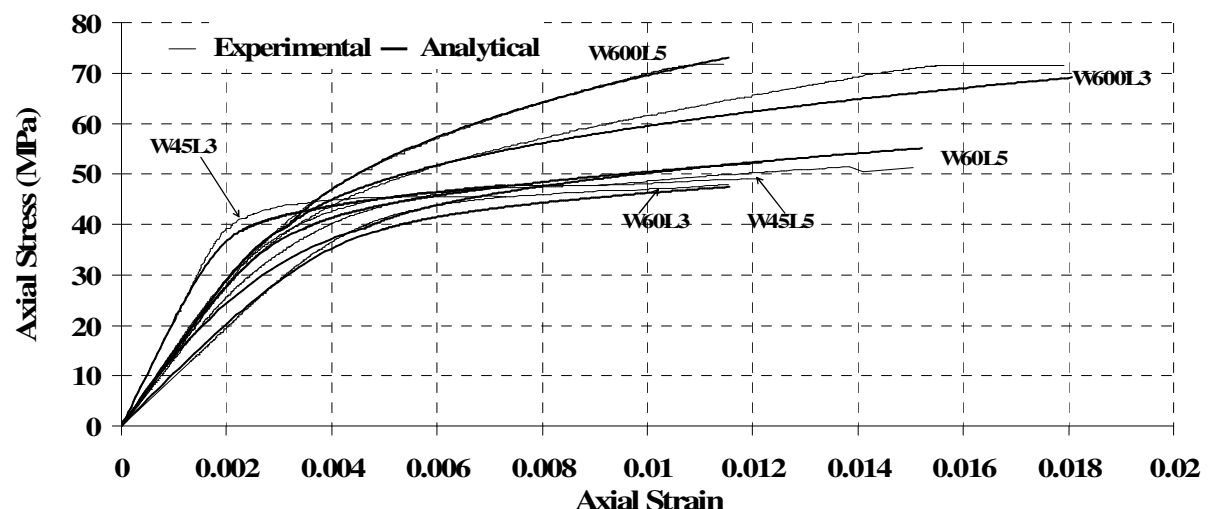

(c)

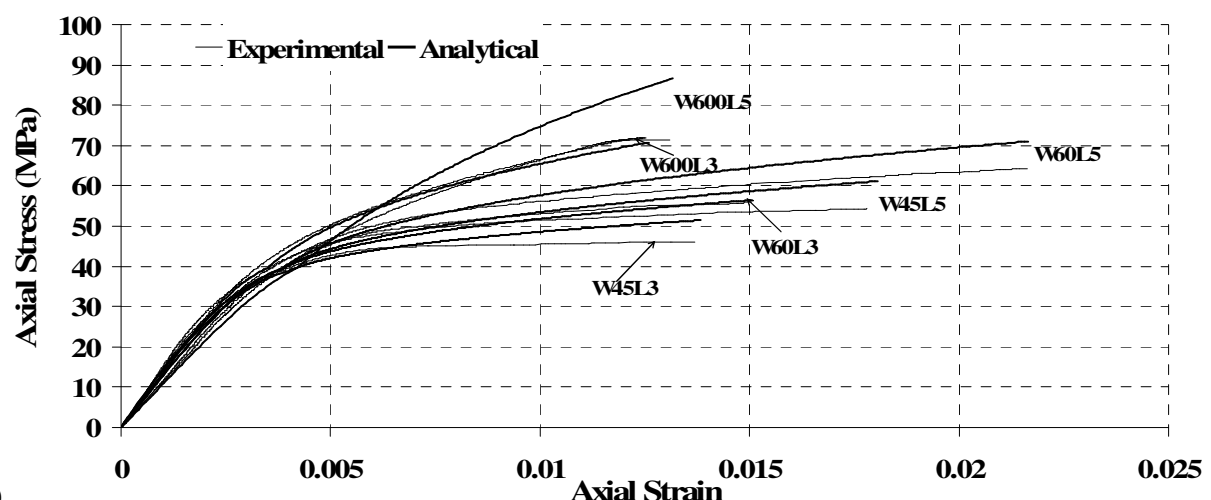

(d)

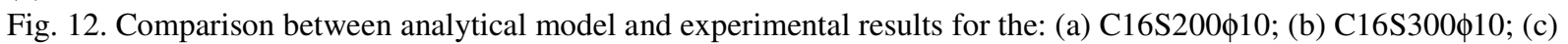
C32S200ф10; (d) C32S300ф10. 